\title{
La recepción de los derivados en -ismo e -ista en la lexicografía española no académica de la primera mitad del siglo XIX*
}

\author{
LAURA MUÑOZ A RMIJO \\ Universidad Autónoma de Barcelona
}

\section{INTRODUCCIÓN}

La lexicografía española monolingüe experimenta una gran evolución en la primera mitad del siglo XIX. La aparición de una nueva técnica lexicográfica característica de los diccionarios no académicos propicia la ruptura del monopolio y del exclusivismo de la Real Academia Española vigentes hasta esta época. Este grupo de diccionarios, calificados en la historia de la lexicografía como «no académicos»o «extra-académicos» por sus criterios divergentes respecto a la Corporación académica ante la recepción de neologismos y voces técnicas, posee en común ofrecerse «como superadores del caudal léxico del $D R A E$ (Diccionario de la Real Academia Española), si bien todos ellos, sin excepción, lo utilizan como fuente principal, o en algunos casos, son plagios descarados del texto académico» (Azorín y Baquero Mesa 19941995: 10).

El propósito de esta investigación es observar el distinto enfoque que existe en las dos tendencias lexicográficas españolas de la primera mitad del siglo XIX. Para ello, se ha elegido una muestra representativa: los derivados en -ismo e -ista incorporados en estos dos tipos de diccionarios. La finalidad de este estudio reside en la comparación del distinto tratamiento que recibe este tipo de léxico en ambas tradiciones. Se trata, por un lado, de comprobar si realmente existen en las ediciones del $D R A E$ y en los diccionarios no académicos de este periodo las concepciones tan divergentes ante la incorporación de léxico científico y técnico que han sido señaladas en las principales investigaciones (Azorín 2000, Baquero Mesa 1992, Seco 1987); por otro lado, se pretenden presentar las diferencias de este tipo de léxico, los derivados en -is$m o$ e -ista, en los diccionarios de la tradición académica y en los de la no académica. Ambos sufijos forman derivados cuyos principales significados corresponden, en el caso de los sustantivos en -ismo, a doctrinas de diferentes áreas (científicas, culturales, políticas y religiosas), fenómenos científicos o diferentes tipos de conductas humanas. Por su parte, el sufijo -ista forma sustantivos y adjetivos que pueden referirse a los partidarios de cualquier doctrina, a diferentes profesiones o bien a diferentes tipos de comportamientos humanos. De acuerdo con estos significados, una gran parte de los derivados en -ismo e -ista pertenece al léxico científico y técnico ya que se relaciona con campos específicos de la ciencia, la medicina, la técnica, la política y contribuye en la creación de un gran número de conceptos y realidades.

* La investigación necesaria para desarrollar este trabajo ha sido parcialmente financiada con la ayuda de la DGICYT para el proyecto Banco de datos diacrónico e hispánico: morfología léxica, sintaxis, etimología y documentación ( $\mathrm{n}^{\circ}$ de referencia HUM2005-08149-C02-01/FILO) y con el apoyo del Comissionat per Universitats i Recerca de la Generalitat de Catalunya concedido al Grup de Lexicografia i Diacronia $\left(\mathrm{n}^{\circ}\right.$ de referencia SGR2005-00568).

LAURA MuÑz ARMiJo, « La recepción de los derivados en -ismo e -ista en la lexicografía española no académica de la primera mitad del siglo XIX», Revista de Lexicografia, XIII (2007), pp. 75- 104. ISSN: 1134-4539, e-ISSN: 2603-667. DOI: https://doi.org/10.17979/rlex.2007.13.0.4787 
Tras la publicación del Diccionario de la lengua castellana (1825) de Núñez de Taboada, en los años posteriores se elabora una cantidad importante de diccionarios que configuran una situación inexistente hasta entonces en el panorama de la lexicografía anterior. El primero en publicarse es el Diccionario de la lengua castellana por la Academia Española (1826) de Cristóbal Pla y Torres. A este le sigue un conjunto de obras que tiene su aparición en los años cuarenta: el Panléxico. Diccionario universal de la lengua española (1842) de Juan Peñalver, el Diccionario de la lengua castellana con las correspondencias catalana y latina (1844-1846) de Pedro Labernia y el Nuevo diccionario de la lengua castellana (1846) de Vicente Salvá.

En este salto temporal de veinte años -los que distan entre el diccionario de Núñez de Taboada (1825) y la década de los años 40-, surge un número representativo de diccionarios en los se produce un cambio de enfoque que consiste en la recopilación masiva de voces con el objetivo de superar la lista de términos del $D R A E$. Esta práctica implica la aparición de un nuevo género en el terreno de la lexicografía española a finales de la primera mitad del siglo XIX: el diccionario enciclopédico. Algunos de los diccionarios españoles en los que se percibe esta nueva técnica lexicográfica son el Diccionario nacional o gran diccionario clásico de la lengua española (1846-1847) de Ramón Joaquín Domínguez, el Gran diccionario de la lengua española (1852) de Adolfo de Castro, el Diccionario enciclopédico de la lengua española (1853-1855) de la librería Gaspar y Roig y el Vocabulario de todas las voces que faltan a los diccionarios de la lengua castellana (1857) de Luis Marty y Caballero.

En este grupo de diccionarios es destacable la gran influencia que ejerce la lexicografía francesa que básicamente se explica por motivos políticos y económicos. En estos años las circunstancias políticas de este periodo promueven el exilio de los lexicógrafos españoles al país francés. De acuerdo con la explicación de Seco (1987), la ruptura del comercio entre España y las colonias españolas de América origina en Francia la petición de un gran número de lexicógrafos para poder abastecer la gran demanda de diccionarios en los países americanos. Entre ellos cabe destacar la presencia de Vicente Salvá y Ramón Joaquín Domínguez que viajaron a Francia con el fin de publicar varios diccionarios y de fundar en este país su propia editorial. A raíz de este contacto con la lexicografía francesa tiene lugar «un incipiente pluralismo en la producción de diccionarios que, finalmente, traería como consecuencia el ensayo de nuevas forma de concebir el diccionario de la lengua» (Azorín y Baquero Mesa 1996: 9) entre los lexicógrafos no académicos españoles. ${ }^{1}$

Desde el punto de vista metodológico, para la obtención del corpus de este estudio se han consultado los derivados en -ismo e -ista adicionados en los diccionarios no académicos de la primera mitad del siglo XIX que se encuentran informatizados en la versión en DVD del Nuevo Tesoro Lexicográfico de la Lengua Española (NTLLE). Se han elegido los cinco diccionarios de la primera mitad del siglo XIX que figuran en esta fuente electrónica: el Diccionario de la lengua castellana de Núñez de Taboada de 1825 (\$ 2.1.), el Nuevo diccionario de la lengua castellana de Salvá (§ 2.2.) publicado en 1846, el Gran diccionario de la lengua española

\footnotetext{
${ }^{1}$ Estas dos formas de proceder - la aperturista propia de los diccionarios no académicos y la conservadora, característica de la Corporación-, se ha descrito como un conflicto de paradigmas (Esparza 1992) o con la distinción diccionario selectivo vs. diccionario extensivo, realizada por Menéndez Pidal (1945).

${ }^{2}$ En la versión en DVD del NTLLE se encuentra informatizada la edición de 1853 de este diccionario. Los ejemplos y el número de voces en -ismo e -ista que se presentan de este diccionario en el presente estudio proceden de esta edición.
} 
de Castro y Rossi de 1852 (§ 2.3.), el Diccionario nacional o gran diccionario clásico de la lengua española (1846-1847) de Domínguez ${ }^{2}$ (\$ 2.4.) y, finalmente, el Diccionario enciclopédico de la lengua española de la editorial de Gaspar y Roig (§ 2.5.) aparecido en $1853 .^{3}$

Los datos obtenidos con el NTLLE se han contrastado con las incorporaciones de los derivados en -ismo e -ista en las ediciones del $D R A E$ de la primera mitad del siglo XIX. ${ }^{4}$ Con todo ello se ha elaborado una base de datos en la que se han introducido los derivados documentados en ambas tradiciones lexicográficas para poder comparar las diferencias existentes en ambos enfoques.

Junto a estas fuentes de estudio también se ha tenido en cuenta la existencia de otros corpus informatizados, como la versión en CD del Trésor de la Langue Française Informatisé y la versión electrónica del Dictionnaire national, ou dictionnaire universel de la langue française de Bescherelle (1843) (http://www.gallica.bnf.fr/), ${ }^{5}$ con el fin de observar la influencia que ejerce la lexicografía francesa en algunos de los diccionarios no académicos de este periodo.

\section{LOS DERIVADOS EN $-I S M O$ E $-I S T A$ EN LA LEXICOGRAFÍA NO ACADÉMICA DE LA PRIMERA MITAD DEL SIGLO XIX}

En la primera mitad del siglo XIX existe una constante que se repite a lo largo de los diccionarios no académicos publicados en este periodo: la crítica a la Corporación académica consistente en la descalificación y el triunfalismo por superar el caudal académico. Esta característica básica se mantiene en los cinco repertorios lexicográficos que se van a comentar en los apartados posteriores: Núnez de Taboada (1825), Salvá (1846), Castro y Rossi (1852), Domínguez (1853) y, finalmente, el de la editorial Gaspar y Roig (1853-1855). A pesar de compartir este espíritu reaccionario en contra de la Academia, cada uno de estos cinco diccionarios posee unas características particulares.

\subsection{El Diccionario de la LENGUA CASTELlana DE NúÑEZ DE TABOADA (1825)}

\subsubsection{Características generales}

Como ya han apuntado varios investigadores (Seco 1987; Azorín 1994, 1996, 2000; Baquero Mesa 1992; García Platero 2003) este autor es el primero que sigue la línea iniciada un siglo antes por Terreros y registra en su obra voces de reciente creación. ${ }^{6}$

${ }^{3}$ Por motivos prácticos no se han incluido todos los diccionarios no académicos que existen en la primera mitad del siglo XIX desde la publicación del Diccionario de la lengua castellana de Núñez de Taboada en 1825, como puede ser el Diccionario universal de la lengua castellana de Juan de Peñalver (1842) o el Diccionario general de la lengua castellana de Cipriano de Arnedo y José Caballero (1849), ya que algunos de ellos no están informatizados en el DVD del NTLLE.

${ }^{4}$ También nos servimos del NTLLE para la consulta de los diccionarios académicos. A raíz de investigaciones anteriores sobre los derivados en -ismo e -ista, se ha partido de la base de datos confeccionada para el trabajo de investigación de Muñoz Armijo (2005).

${ }^{5}$ En esta página web se presenta la cuarta edición en dos tomos de este diccionario, publicada en 1856. Los datos y los ejemplos que se han extraído de este diccionario en este estudio proceden de esta cuarta edición.

${ }^{6}$ Según Anglada y Bargalló (1992: 956), Núñez de Taboada es el continuador de la doble vía abierta por Terreros en la lexicografía española: por un lado, «en el camino de inflación léxica que en el siglo XIX seguirán con fortuna desigual lexicógrafos como Peñalver, Labernia, Domínguez, Salvá, Castro y otros...» y, por otro lado, representa «el germen del diccionario enciclopédico al ser el suyo un diccionario abierto al ámbito no sólo de la significación, sino también de la designación y de las terminologías». 
En este sentido, la obra de Núñez de Taboada destaca por ser la primera en el siglo XIX que practica la labor de adicionar material lexicográfico nuevo y de corregir definiciones del $D R A E$. En el título completo de la obra de Núñez de Taboada el mismo autor lo reconoce y resume la metodología usada para la confección del diccionario: Diccionario de la lengua castellana para cuya composición se han consultado los mejores vocabularios de esta lengua, y el de la Academia Española últimamente publicado en 1822, aumentado con más de 5000 voces o artículos que no se hallan en ninguno de ellos.

Precisamente por el carácter novedoso de esta obra en el siglo XIX, el diccionario de Núñez de Taboada, en palabras de Platero (2003: 268), «es quizá el más conocido de los repertorios lexicográficos del primer cuarto de siglo. Se trata de una obra que influyó en otros catálogos posteriores»), como en el de Peñalver (1842) o en el de Salvá (1846). Las incorporaciones de Núñez de Taboada son básicamente voces de la lengua común, de estilo familiar y, finalmente, voces técnicas que pretenden reflejar «su entorno socio-cultural» (Baquero Mesa 1992: 456). La forma de proceder de este lexicógrafo evidencia una disparidad de criterios frente a la postura normativista y restrictiva de la Corporación en el primer cuarto del siglo XIX. De este modo, Núñez de Taboada es el precursor de una tendencia aperturista hacia la entrada en el Diccionario de la lengua castellana de voces de uso reciente en la lengua.

\subsubsection{Incorporación de lemas en-ismo $e$-ista}

La obra de Núñez de Taboada presenta un mayor número de incorporaciones de lemas en -ismo e -ista que las ediciones del $D R A E$ de la primera mitad del siglo XIX. Al comparar las entradas que figuran en cada uno de estos diccionarios puede comprobarse que la obra de Núnez de Taboada recoge unas $54^{7}$ voces más que el $D R A E$ en su sexta edición $(1822)^{8}$ y que comparte con el Diccionario académico un total de 384. Estos datos confirman que el número de palabras comunes a estas dos obras es mayor al de voces no compartidas pues el autor, como manifiesta en el título de la obra, parte del cuerpo de la edición académica de 1822 a la que incorpora algunas, un total de 5000 voces nuevas y algunas modificaciones.

Algunas de las aportaciones propias del primer diccionario no académico de Núñez de Taboada pasan a formar parte de la nomenclatura del $D R A E$ en las ediciones posteriores de la segunda mitad del siglo XIX y del XX. De las 54 voces adicionadas en la obra lexicográfica de

${ }^{7}$ A continuación se enumeran: anglicanismo, atomismo, balista, balista, caravanista, cenismo, cinismo, civismo, confesionista, conformista, congruismo, congruista, decisionista, druidismo, eufemismo, falangista, filosofismo, floretista, galenismo, galvanismo, gasconismo, germanismo, gongorista, harmonista, idealismo, independientismo, inmaterialista, inoculista, magismo, mamarrachista, metacronismo, monarquista, monopolista, neografismo, noctambulismo, paradoxismo, peripatetismo, pirronista, politeísta, procreonismo, republicanismo, sabeísmo, sacrista, saduceismo, targumista, teísmo, teísta, terrorismo, terrorista, tomismo, triteismo, triteísta, ubiquista, zenonismo. Estos datos se relacionan con los que obtienen otras investigaciones (Azorín 1996, Baquero Mesa 1992).

${ }^{8}$ Hasta la sexta edición (1822) del DRAE se ha contado un total de 384 incorporaciones en -ismo e -ista que contrasta con las 441 del diccionario Núñez de Taboada. Estas 384 adiciones corresponden a las voces nuevas con ambos sufijos que se añaden en el $D A$ hasta la sexta edición de 1822 . Desde estas primeras voces del $D A$, se ha observado el crecimiento de las adiciones nuevas en cada una de las ediciones posteriores del $D R A E$ comparando el número de adiciones nuevas de la edición posterior con respecto a la anterior, hasta llegar a la sexta edición (1822). Frente a las 384 incorporaciones nuevas en -ismo e -ista en las ediciones del DRAE en el Diccionario de Núñez de Taboada aparece un total de 441 voces en -ismo e -ista. 
Núñez de Taboada, 35 de ellas se documentan en el $D R A E$ después de 1825 (1 en 1832, 3 en 1852, 13 en 1869, 8 en 1884, 4 en 1899, 1 en 1914, 2 en 1925, 2 en 1970 y 1 en 1984). ${ }^{9}$ Estos datos destacan la modernidad del diccionario de Núñez de Taboada. Además, la mayoría de estas voces han pervivido hasta la actualidad. El conjunto de estos 35 términos se caracteriza por pertenecer a un léxico culto y enciclopédico, pues son palabras técnicas que se refieren a doctrinas religiosas (idealismo, sabeísmo, saduceísmo, tomismo), a fenómenos científicos (atomismo, noctambulismo) o a los partidarios de doctrinas políticas o religiosas (conformista, confesionista, falangista). ${ }^{10}$

Existen, además, otras palabras que nunca han sido acogidas en el Diccionario académico. En este conjunto de voces, un total de 18, que no se han consolidado en el léxico español se observan tres tipos de términos en -ismo e -ista . ${ }^{11}$ En primer lugar, neologismos que pertenecen al léxico religioso (triteísmo, triteísta, zenonismo) o bien al léxico científico y técnico (inmaterialista, inoculista, peripatetismo, procreonismo). Estos neologismos posiblemente no obtuvieron una gran aceptación y, por esta razón, no se llegan a documentar en el $D R A E$. Los escasos testimonios de estas voces en el Corpus diacrónico del español (CORDE) y en el Corpus del español de Mark Davies también confirman el poco uso de estos términos en el caso de la lengua escrita. No existe ningún testimonio escrito en los corpus citados para las voces inoculista, procreonismo, triteísta y zenonismo. Sólo los lemas inmaterialista, triteísmo y peripatetismo presentan alguna documentación; los dos primeros en la primera mitad del siglo xx y el último, peripatetismo, en el siglo XVIII en el Theatro crítico universal de Feijoo. ${ }^{12}$

Este último derivado, peripatetismo, se ha formado a partir del adjetivo peripatético, -ca que existe desde el siglo XV en textos de carácter filosófico y científico ${ }^{13}$ y en el $D A$ (1737) se define como «el seguidor de la filosofía de Aristóteles». El significado de este derivado en -ico es el mismo que el de los sustantivos y adjetivos en -ista que designan a los partidarios de una doctrina. Entre las voces peripatetismo y peripatético se establece una relación de equivalencia, semejante al sistema por parejas entre los derivados en -ismo e-ista, que corresponde

${ }^{9}$ Son: anglicanismo (1869), atomismo (1869), balista (1884), cenismo (1925), cinismo (1869), civismo (1869), confesionista (1869), conformista (1869), congruismo (1869), congruista (1869), druidismo (1884), eufemismo (1884), falangista (1970), filosofismo (1852), floretista (1852), galenismo (1884), galvanismo (1852), germanismo (1869), gongorista (1970), harmonista (1899), idealismo (1869), magismo (1984), mamarrachista (1869), monopolista (1869), noctambulismo (1925), politeísta (1884), republicanismo (1899S), sabeísmo (1884), sacrista (1832), saduceísmo (1899), teísmo (1884), teísta (1899), terrorismo (1869), terrorista (1884), tomismo (1914).

${ }^{10}$ Esta voz es la única del grupo de adiciones de Núñez de Taboada que aparece con posterioridad en alguna edición del $D R A E$ con un cambio de significado. La definición que aparece en Núñez de Taboada es «soldado de una falange» y la que aparece en el $D R A E-1970$ se relaciona con la situación política tras la Guerra Civil española «Persona afiliada a la Falange Española». De acuerdo con estas descripciones se puede hablar de dos términos diferentes porque responden a dos conceptos distintos.

${ }^{11}$ Son las siguientes: caravanista, decisionista, gasconismo, indenpendientismo, inmaterialista, inoculista, metacronismo, monarquista, neografismo, paradoxismo, peripatetismo, pirronista, procreonismo, targumista, triteísmo, triteísta, ubiquista y zenonismo.

${ }^{12} \mathrm{La}$ cita de esta documentación en el CORDE es la siguiente: «Por tanto, los que se dedican a la Philosofía, mirándola, no precisamente como escala para subir a la Theología escolástica, sino como un instrumento para examinar la naturaleza, pueden, sin sujetarse servilmente al peripatetismo, buscar la verdad por el camino que les parezca más derecho, pero sin perder jamás de vista los dogmas sagrados» (Feijoo, Benito Jerónimo (1728): Theatro crítico universal, o discursos varios en todo género de materias, para desengaño de errores ...).

${ }^{13}$ El primer testimonio escrito se encuentra en la obra Visión deleytable (1430-1440) de Alfonso de la Torre. 
al nombre de una doctrina y a su seguidor. El neologismo peripatetismo se documenta en una fecha posterior a peripatético en la lengua escrita y se crea para nombrar los conceptos teóricos que comparten este grupo de personas. La formación de sustantivos que describen doctrinas o ideologías es uno de los significados más frecuentes del sufijo -ismo y, en este sentido, se explica la aparición del lema peripatetismo en los diccionarios no académicos de Núñez de Taboada (1826), Domínguez (1846), Gaspar y Roig (1853) y Zerolo (1895) y en los tratados filosóficos de Feijoo (1728) o Menéndez Pelayo (1880-1881)

En un segundo grupo, se encuentran variantes en -ismo e-ista de otras palabras que no se han consolidado en el DRAE. Así, independientismo es variante del término independentis$m o$. La primera de ellas únicamente aparece en el diccionario de Terreros (1786-1788) y en el de Núñez de Taboada (1825). En cambio, la forma independentismo se incorpora un siglo más tarde en la edición de 1970 y no se documenta en ninguno de los diccionarios no académicos del siglo XIX. Como se puede comprobar en las definiciones que aparecen en estos diccionarios el significado de esta palabra no cambia y se refiere a los partidarios de la independencia política o religiosa:

\section{Independientismo}

Secta de herejes, que componían una especie de Anarquía, que destruye toda dependencia, superioridad, y distinción en la Iglesia, y en el Gobierno (Terreros 1786-1788).

Secta de los independientes (Núñez de Taboada 1825).

En un país que no tiene independencia política, movimiento que la propugna o reclama (DRAE1970).

La existencia de estas dos variantes tiene implicaciones morfológicas y fonéticas. En cada una de ellas el sustantivo en -ismo se ha formado a partir de una base léxica distinta: independiente para el sustantivo independientismo e independente para el derivado independentis$m o$. En el primero de los casos el sufijo -ismo se adjunta directamente a la raíz léxica independiente sin generar ninguna alternancia vocálica, es decir se mantiene el diptongo de la base a pesar de tener una posición inacentuada.

En cambio, en la segunda variante se pueden considerar dos interpretaciones. Por un lado, la base léxica del derivado es independente y el sustantivo que se obtiene como resultado de este proceso es independentismo sin la presencia del diptongo /iél. Por otro lado, la base léxica de este derivado puede ser independiente y la adjunción del sufijo -ismo origina, desde el punto de vista fonético, una monoptongación de esta base: independentismo. La monoptongación del diptongo /ié/ «sucede en los verbos y otros derivados a partir de sustantivos diptongados» $\mathrm{y}$ «los cultismos favorecen su aparición» (Pensado 1999: 4471). Ambas explicaciones son posibles; la existencia en la lengua de las dos bases léxicas desde el siglo XVIII, independiente e independente, ya es suficiente para explicar esta alternancia en la formación de los dos sustantivos en -ismo.

En la última clase de términos, se agrupan las voces que en el $D R A E$ aparecen expresadas con otros sufijos. Las voces monarquista o pirronista, propias del diccionario de Núñez de Taboada, se documentan en el DRAE adjuntadas respectivamente a otro sufijo: monárquico,

${ }^{14}$ La obra de Menéndez y Pelayo (1880-1881) en la que aparece el derivado peripatetismo es Historia de los heterodoxos españoles. 
pirroniano o pirrónico. Únicamente pirrónico se recoge también en la obra de Núñez de Taboada. La voz monárquico aparece desde la primera edición de 1780 con el significado característico de los adjetivos relacionales, es decir, especifica el ámbito o el dominio que corresponde a alguna persona o cosa. En cambio, en la definición del derivado monarquista se circunscribe al seguidor de una ideología política. El significado de ambos términos no es el mismo y ambos ejemplos no se pueden concebir como variantes de una misma palabra:

\author{
Monarquista \\ Partidario de la monarquía (Núñez de Taboada 1825). \\ Monárquico \\ Lo que pertenece, ó es propio del monarca, ó monarquía (DRAE-1780).
}

Cabe destacar que en la duodécima edición del $D R A E$ (1884) monárquico incorpora una segunda acepción que se refiere a los seguidores de la monarquía; este significado es el mismo que aparece en Núnez de Taboada (1825):

\title{
Monárquico
}

Perteneciente ó relativo al monarca ó á la monarquía. || Partidario de la monarquía (DRAE-1884).

La incorporación de monarquista ${ }^{15}$ en el diccionario de Núñez de Taboada se explica por la analogía con el significado de 'partidario o seguidor de una doctrina' que designa una gran parte de derivados creados con el sufijo -ista y por el auge de este sufijo en esta época.

Por lo que respecta a las variantes pirroniano y pirrónico también se encuentran en textos escritos con una fecha anterior a su incorporación en el $D R A E$. Así, pirrónico aparece en un texto de 1790 y en el $D R A E$ se documenta posteriormente en la quinta edición (1817). La voz pirroniano, en cambio, se incorpora el $D R A E-1936$ a pesar de que en el CORDE existen testimonios ya en el siglo XVIII. A diferencia de ello, no se ha encontrado ninguna presencia en el $C O R D E$ de la variante pirronista que recoge el diccionario de Núñez de Taboada.

En definitiva, la existencia de las variantes monárquico, pirroniano y pirrónico explica en parte el hecho de que las voces monarquista y pirronista no sean admitidas en el $D R A E$; su presencia en Núñez de Taboada indica el empuje creador de -ista en el siglo XIX.

Las adiciones de Núñez de Taboada estudiadas responden al «enfoque sincrónico descriptivo» de este lexicógrafo (Baquero Mesa 1992: 456) y a la conexión con su entorno sociocultural.

Además de la sexta edición (1822) del $D R A E$ existen otras fuentes en el diccionario de Núñez de Taboada. Algunas voces con ambos sufijos se han encontrado con anterioridad en el diccionario de Terreros (1786-1788) y no aparecen en la sexta edición del $D R A E$ sino que se incorporan con posterioridad en el repertorio académico. Esta posible influencia del diccionario de Terreros se ha podido observar en el grupo de derivados que son contribuciones originales

${ }^{15}$ En el CORDE destaca un mayor predominio del derivado en -ico desde el siglo XVI con el significado del adjetivo relacional de 'perteneciente o relativo a la monarquía'. A diferencia de las 505 documentaciones encontradas en este corpus para la voz monárquico, en el derivado monarquista se observan pocos testimonios escritos. Las 25 documentaciones que aparecen en el CORDE son posteriores a la obra de Núñez de Taboada y todas ellas remiten a obras de autores hispanoamericanos. La primera documentación de esta voz se encuentra en la obra Juicio crítico de Don José Gómez Hermosilla de Andrés Bello (1841-1842). 
del diccionario de Núñez de Taboada. De las 54 aportaciones que se han considerado propias de este lexicógrafo, por el hecho de no aparecer con anterioridad en el $D R A E$, un total de 14 lemas aparece antes en la obra de Terreros; son los siguientes: confesionista, conformista, congruismo, congruista, idealismo, optimismo, optimista, papismo, platonismo, rapsodista, saduceísmo, tomista, triteísmo, ubiquista. A excepción de las voces rapsodista, triteísmo y ubiquista que no llegan a documentarse en el Diccionario académico por pertenecer a alguno de los tres tipos de voces que se ha descrito anteriormente, el resto de términos se incluye en las ediciones del $D R A E$ de la segunda mitad del siglo xIX o bien del siglo xx: tomista (DRAE-1832), optimismo (DRAE-1852), optimista (DRAE-1852), confesionista (DRAE-1869), conformista (DRAE1869), congruismo (DRAE-1869), congruista (DRAE-1869), idealismo (DRAE-1869), platonismo (DRAE-1899), saduceísmo (DRAE-1899) у papismo (DRAE-1936).

En estos casos cabe valorar la hipótesis de la influencia que pudo ejercer el diccionario de Terreros en la elaboración del Diccionario de la lengua castellana de Núñez de Taboada. La comparación de las definiciones de los catorce lemas anteriores en ambos diccionarios, el de Terreros y el de Núñez de Taboada, no permite demostrar que estas voces del diccionario de Núñez de Taboada proceden de la obra de Terreros. Las definiciones de los catorce lemas no son una copia literal del diccionario de Terreros. Las diferencias que se observan en ellas responden fundamentalmente a una variación en la técnica lexicográfica de Núñez de Taboada, como se puede observar en los siguientes ejemplos:

\section{Congruista}

En la Teología, el que lleva la Gramática congrua. Fr. Congruiste. Lat. Qui gratiam congruam defendit. Los congruistas dicen que la gracia congrua logra su efecto, porque Dios la da en el instante que la ve eficaz, y por eso la llaman también eficaz, y oportuna (Terreros 1786-1788).

El que defiende la opinión de la congruencia (Núñez de Taboada 1825).

Saduceísmo

Error de los Saduceos. Fr. Saduceisme (Terreros 1786-1788).

Doctrina de los saduceos (Núñez de Taboada 1825).

Algunos investigadores (Baquero Mesa 1992, Azorín 2000) ya han señalado la influencia de Terreros en los diccionarios no académicos del siglo XIX.

\subsection{Nuevo diccionario de La LENGUa CaStellana De SALVÁ (1846)}

\subsubsection{Características generales}

El diccionario de Salvá es uno de los más valorados en los estudios de la lexicografía española del siglo XIX. La existencia de un gran número de artículos e investigaciones sobre las características de esta obra así lo atestiguan (Azorín 1996, 2000, Baquero Mesa 1992, García Platero 2003, Seco 1987). ${ }^{16}$

El mismo autor justifica en la Introducción de su diccionario la metodología que ha seguido para la confección de su obra:

${ }^{16}$ El diccionario de Salvá es una de las obras que más investigaciones ha recibido. Conviene destacar la atención que Azorín ha dedicado a este lexicógrafo (1994-1995, 1996, 1996-1997, 2000, 2003). Según esta investigadora el diccionario de Salvá es «el primer ejemplo de diccionario moderno de la historia de la lexicografía española monolingüe» y, en definitiva, «la obra cumbre de la lexicografía española no académica del siglo XIX» (Azorín 1996: 53). 
La nona edición es más completa de vocablos y más purgada de defectos de redacción que ninguna otra de las anteriores, y yo no podía vacilar en adoptarla por texto e incorporar en ella mis adiciones, ya que no tengo espacio para construir un diccionario de planta. Me he decidido pues a reproducirla sin omitir cosa alguna, aumentándola con las voces, acepciones y frases, etc. Que tenía recogidas, y rectificando las definiciones y correspondencias latinas; pero de modo que siempre aparezca lo que es de mi cosecha [...] Con este fin he deslindado mi trabajo del académico del modo siguiente: son enteramente míos los artículos que llevan la + ; en los notados con un * me pertenece todo lo que va incluso dentro de paréntesis cuadrados [ ], y el / denota que se ha mudado el artículo del sitio que equivocadamente ocupaba, o se ha dado nuevo orden a sus partes, o se ha rectificado algo la redacción (Introducción: XXI).

El fragmento anterior señala la fuente básica del diccionario de Salvá, la novena edición del DRAE (1843), y algunas cuestiones metodológicas que tuvo en cuenta el autor para realizar su obra. En realidad, toda esta Introducción constituye la doctrina lexicográfica de Salvá y, en palabras de Azorín y Baquero Mesa (1996-1997), «los presupuestos teóricos que sustentaban su modelo de "diccionario ideal"», esto es, «las ideas acerca de los contenidos y de los aspectos formales de su modelo de diccionario de la lengua».

Las principales novedades en las adiciones de Salvá tienen lugar en los derivados técnicos y en las voces americanas. En las páginas preliminares de su obra el lexicógrafo denuncia el desconocimiento por parte de la Corporación del español de América y las Filipinas. La atención que Salvá prestó a los términos americanos ha llevado a considerarlo el «pionero español del americanismo dentro de nuestra lexicografía» (Seco 1987: 145). Junto a estos tipos de voces, un alto número de lemas de la macroestructura corresponde a los términos antiguos.

Del mismo modo que a su predecesor, Núñez de Taboada, a Salvá también le preocupa la necesidad de incorporar en su diccionario los neologismos más recientes que reflejan los acontecimientos socio-culturales más importantes de su época y en su obra pretende «vincular el diccionario a la realidad circundante» (Baquero Mesa 1992: 458).

\subsubsection{Incorporación de lemas en-ismo $e$-ista}

Siguiendo los preceptos básicos de la lexicografía no académica, el Nuevo diccionario de Salvá pretende ser una «obra abarcadora» (García Platero 2003: 269), al igual que la de su antecesor Núñez de Taboada. La nómina de este lexicógrafo presenta un mayor número de incorporaciones de lemas en -ismo e -ista que la novena edición (1843) del DRAE; aproximadamente, el diccionario de Salvá contiene unos 100 términos más que la novena edición (1843) del Diccionario académico.

Se ha podido observar que algunas de estas voces, como por ejemplo anatocismo, chasquista, clamista o chupatismo, no aparecen por primera vez en la obra de Salvá. Se trata de términos que formaron parte de la macroestructra del Diccionario de Autoridades y se suprimieron en la segunda edición (1770) o en la primera edición en un tomo del Diccionario de la Academia (1780). Estos mismos lemas se introducen en la obra del lexicógrafo valenciano con el mismo significado que aparecía en Autoridades.

Estos términos son voces de autor, es decir, derivados de creación literaria acuñados por algunos autores literarios y que el Diccionario de Autoridades incorpora en su nómina. ${ }^{17} \mathrm{De}$

\footnotetext{
${ }^{17}$ En la tesis doctoral de Freixas (2003) se estudia este tipo de voces y se presenta a Francisco de Quevedo como uno de los autores más citados en el Diccionario académico que inventa estas creaciones literarias (véase el capí-
} 
acuerdo con Garrido Moraga (1982: 277), la Academia decidió suprimir este tipo de voces -las inventadas por los autores, principalmente de Quevedo y Góngora-, en la segunda edición del Diccionario de Autoridades. ${ }^{18}$ Este criterio se mantiene en la primera edición en un tomo (1780) en la que se suprimen las voces chaquista, clamista y chupatismo, ${ }^{19}$ también de creación literaria. ${ }^{20}$ La aparición de estos derivados en el Nuevo diccionario de Salvá se explica por la intención de este lexicógrafo de incorporar un número de términos superior al Diccionario académico:

Hubo también en el siglo XIX lexicógrafos que, movidos por un afán coleccionista y de exhaustividad, y con Autoridades delante, decidieron recuperar «quevedismos» que, figurando en Autoridades, habían sido excluidos, como ya sabemos del diccionario usual. Así lo hizo, por ejemplo, Salvá en su Nuevo diccionario de la lengua castellana (1846), y otros diccionaristas le imitaron (Álvarez de Miranda 2004: 411).

Junto con la posible influencia del $D A$ también se ha observado que estas palabras, excepto el lema chupatismo, además de estar recogidas en Autoridades se encuentran en la nómina del diccionario de Terreros (1786-1788). Ante el escaso predominio de estos derivados en la lengua escrita del siglo XIX hay que suponer que ambos repertorios, Autoridades y Terreros, pudieron influir en la inclusión de estas voces en el Nuevo diccionario de Salvá.

Existe un grupo de términos que corresponde a las adiciones propias (96 lemas) que este lexicógrafo añade a la novena edición del $D R A E(1843)$.

Algunas de estas aportaciones pasan a formar parte de la nomenclatura del $D R A E$ en las ediciones posteriores de la segunda mitad del siglo XIX y del XX. En cambio, existen otras palabras que nunca han sido acogidas en el Diccionario académico. De los 96 términos 54 se recogen en el $D R A E$ a partir de 1846 (10 en 1852, 11 en 1869, 7 en 1884, 3 en 1899, 3 en 1914, 7 en 1925, 4 en 1927, 2 en 1933, 4 en 1936, 2 en 1984 y 1 en 1989). ${ }^{21}$ Estos datos destacan la modernidad del diccionario de Salvá. Además, la mayoría de estas voces ha pervivido hasta la actualidad.

tulo VII de esta tesis doctoral titulado «Inventario de las fuentes del Diccionario de Autoridades»). Según esta investigadora (en prensa), la Corporación no elimina todos los términos de creación literaria en la segunda edición del $D A$ (1770) y en la última edición del $D R A E$ (2001) todavía permanece algún ejemplo de estos sustantivos. Un ejemplo es porciopelo, voz creada por Villaviciosa.

${ }^{18}$ Según el estudio de Garrido Moraga (1982: 274-277), en la segunda edición de Autoridades (1770) se suprime un total de 625 entradas. De esta cantidad un porcentaje del 7.2\%, equivalente a 45 lemas, corresponde a la supresión de voces inventadas o jocosas que dejan de formar parte de esta segunda edición.

${ }^{19}$ El DA (1729) presenta la autoridad de Quevedo en el lema clamista y la de Góngora en la voz chupatismo. El primero de ellos, clamista, se documenta en la obra La hora de todos y la Fortuna con seso (1635) y el segundo, chupatismo, aparece en Góngora en la Comedia del doctor Carlino (1613).

${ }^{20}$ No obstante, la Corporación no llega a suprimir la totalidad de este tipo de voces y algunas de ellas «sobrevivieron a la criba» (Álvarez de Miranda 2004: 400), como se ha demostrado en los estudios de Freixas (2003 y 2004) y Álvarez de Miranda (2004).

${ }^{21}$ Los términos son: calculista (1852), favoritismo (1852), federalismo (1852), folletinista (1852), italianismo (1852), jacobinismo (1852), operista (1852), pianista (1852), protestantismo (1852), provincialismo (1852), antagonismo (1869), charlatanismo (1869), exclusivismo (1869), enciclopedista (1869), gongorismo (1869), hablista (1869), metodista (1869), servilismo (1869), somnambulismo (1869), sonambulismo (1869), tresillista (1869), cuaquerismo (1884), escotismo (1884), espinosismo (1884), legitimista (1884), onanismo (1884), sincronismo (1884), ultramontanismo (1884), federalista (1899), meteorologista (1899), socinianismo (1899), churriguerismo (1914), churriguerista (1914), tropelista (1914), calendarista (1925), coquetismo (1925), espinosista (1925), formulista (1925), ritualista (1925), terminista (1925), virotismo (1925), aurista (1927M), cimbalista (1927M), detallista $(1927 \mathrm{M})$, diccionarista $(1927 \mathrm{M})$, acuatismo $(1933 \mathrm{H})$, almanaquista $(1933 \mathrm{H})$, babtismo $(1936)$, baptista $(1936 \mathrm{H}$ 1992), batismo (1936), cacoquismo (1936), jesuitismo (1984), liturgista (1984) y francesismo (1989M). 
Entre los 37 derivados ${ }^{22}$ que no se han admitido en el $D R A E$ se observan cuatro tipos de términos en -ismo e -ista. En los dos primeros, se encuentran voces vulgares y familiares de la lengua común que la Corporación no documenta en ninguna de sus ediciones -como cabronismo, chabacanismo, chupatismo, muchachismo y trajinista- y neologismos del léxico científico y técnico, que posiblemente no tuvieron mucho éxito en el vocabulario español y, por esta razón, no aparecen en el DRAE: cabriolista, fisiologista y sexcentista.

En un tercer grupo, se encuentran variantes en -ismo e-ista de otras palabras que no ha admitido el DRAE. Así, epicurismo y dialogista son variantes de los términos epicureísmo y dialoguista. ${ }^{23}$ En la última clase de términos, se agrupan las voces de Salvá que en el $D R A E$ aparecen expresadas con otros sufijos. Las voces corsarista, curialista y virgilista de los diccionarios no académicos, se documentan en el $D R A E$ adjuntados respectivamente a otros sufijos: corsario, curialesco y virgiliano. ${ }^{24}$ Excepto el término corsario que también se recoge en Salvá, los términos curialesco y virgiliano no se incluyen en su diccionario. La presencia de ambas variantes, corsario y corsarista, en la obra de Salvá responde a su técnica lexicográfica de introducir el mayor número posible de voces.

El hecho de que algunas de las voces originales de Salvá no se documenten en el DRAE indica la existencia de diferentes criterios en ambas tradiciones lexicográficas para la recepción de los derivados en -ismo e -ista. Del mismo modo que el diccionario del Núñez de Taboada, el de Salvá pretende superar al $D R A E$ en el número de entradas y, de acuerdo con este objetivo, añade una mayor cantidad de voces.

Lo significativo de la comparación entre los derivados en -ismo e -ista de ambos diccionarios es la presencia en la obra de Salvá de 21 de las voces originales, inexistentes en la nómina del DRAE de la sexta edición (1822), que adicionó Núñez de Taboada: cinismo, civismo, decisionista, druidismo, eufemismo, filosofismo, floretista, galenismo, galvanismo, germanismo, gongorista, mamarrachista, monopolista, pirronista, politeísta, republicanismo, sacrista, teísmo, teísta, terrorismo y terrorista. La definición de estas voces tiene una redacción distinta a la que aparece en el diccionario de Núñez de Taboada. Esta característica se relaciona con la técnica lexicográfica que el autor expone en el prólogo del diccionario: incorporación de neologismos y uso de definiciones objetivas, claras y concisas. A continuación se presenta un ejemplo:

\section{Terrorismo}

Sistema político del terror (Núñez de Taboada 1825).

neol. El sistema del terror a que suele recurrirse en las convulsiones políticas (Salvá 1846).

Estos datos indican que estas palabras eran comunes en la época del diccionario de Salvá y este lexicógrafo se dedicó a corregir y establecer sus propias definiciones teniendo como

\footnotetext{
${ }^{22}$ Son las siguientes: aduanista, alegorista, cabriolista, cabronismo, causista, chabacanismo, chancista, corsarista, corsista, cuacarismo, curialismo, curialista, democratismo, dialogista, doricismo, epicurismo, fabrista, fisiologista, ginosofista, institutista, intolerantismo, mediatorista, minutista, muchachismo, naricismo, peñolista, plebeísmo, pontifista, quijotista, reísmo, sexcentista, sinonimista, sofistismo, trajinista, vacuista, vinculista y virgilista.

${ }^{23}$ Estos últimos forman parte de la nomenclatura del $D R A E$ en ediciones posteriores al Nuevo diccionario de Salvá: epicureísmo se incorpora en la duodécima edición (1884) y dialoguista en la décima sexta (1936). El diccionario de Salvá no recoge las variantes epicureísmo y dialoguista; la primera, epicureísmo aparece en el diccionario no académico de Domínguez (1846-1847) y, la segunda, dialoguista, en el de Gaspar y Roig (1853).

${ }^{24}$ Las primeras documentaciones de estos cuatro términos son: corsario (1780), curialesco (1925) y virgiliano (1803).
} 
punto de partida las definiciones del diccionario de Núñez de Taboada. Esta interpretación está en consonancia con lo que señala Baquero (1992: 461) sobre la influencia que ejerce la labor de Núñez de Taboada en la elaboración del diccionario de Salvá: «Salvá incluye al menos 93 voces "originales" de Taboada aunque si se comparan los artículos se observan notables diferencias. Salvá reorganiza los materiales. Pone orden en las acepciones [...] y define con mayor rigor los lemas. Mas como él mismo dijera, siempre es más fácil corregir que crear "ex novo"».

Finalmente, del mismo modo que en el diccionario de Núñez de Taboada en el de Salvá también se documentan algunas voces en -ismo e -ista que anteriormente estaban presentes en la obra de Terreros (1786-1788). Se han encontrado cinco voces en total (epicurismo, naricismo, plebeísmo, reísmo y vacuista) que no se han documentado en ninguna edición del $D R A E$ por los motivos que se han sugerido en la explicación anterior. Se trata de voces jocosas o inventadas como naricismo, variantes de otros lemas, como epicurismo, o bien voces técnicas de la ciencia, como por ejemplo vacuista. Es difícil asegurar que Terreros sea la fuente de estas voces porque existen documentaciones de algunas de ellas en el CORDE desde siglos anteriores. De epicurismo se encuentran testimonios desde 1734 y de naricismo y plebeísmo en el siglo XVII. Sin embargo, otras voces como vacuista no se recogen en ningún texto del CORDE. En cierta manera el diccionario de Terreros es la obra más inmediata a estos diccionarios no académicos de la primera mitad del siglo XIX que se crean con el objetivo de incorporar un mayor número de palabras a la nómina académica. Este propósito común a los diccionarios de Núñez de Taboada y de Salvá debió influir de algún modo en estas obras. Como sugiere Baquero (1992: 460) «todos beben en mayor o menor medida en la $5^{\text {a }}$ edición del DRAE, en Autoridades y en Terreros».

\subsection{GRAN DICCIONARIO DE L A LENGUA ESPAÑOLA DE CASTRO Y Rossi (1852)}

\subsubsection{Características generales}

Como ya se ha indicado en algunos estudios (Baquero Mesa 1992, García Platero 2003) el Gran diccionario de la lengua Española de Castro y Rossi es un diccionario incompleto que nunca llegó a concluirse. Únicamente se logró completar las tres primeras letras del abecedario. $^{25}$

Los pocos estudios encontrados sobre este diccionario coinciden en señalar su carácter histórico. Este rasgo se explica por el origen de las diferentes fuentes que tiene en cuenta para su elaboración:

que van desde el Diccionario de vocablos castellanos de Sánchez de la Ballesta (1587), pasando por el Diccionario español e inglés de Giral del Pino (1763), hasta el último de la Academia, la edición novena de 1843. El resultado es un producto próximo a un diccionario histórico, entendiendo por ello aquél que se ocupa de la historia de una voz, pero con testimonios procedentes de textos lexicográficos y no lexicográficos (Baquero Mesa 1992: 458).

A diferencia de los diccionarios no académicos comentados en este estudio, el de Castro y Rossi se basa en textos que no son puramente lexicográficos y en este sentido debe destacarse su componente histórico. En el breve prólogo de esta obra se manifiesta la metodología que se ha seguido para la confección de este diccionario:

${ }^{25}$ En concreto, la letra $\mathrm{C}$ tampoco está completa y termina en el lema costra. 
Su objeto, como se puede ver, no ha sido otro que hacer un cotejo de todos cuantos libros de esta clase se han publicado hasta el día de hoy, más dignos de tenerse en cuenta, para fijar la verdadera significación de las voces. La mayor parte de ellas van acompañadas de algunos textos de los escritores notables, en donde se hallan usadas según sus diversas significaciones, único modo de que un Diccionario pueda lograr la autoridad necesaria a sus lectores (Prólogo: 1).

Entre la influencia de los diccionarios españoles cabe destacar las posibles fuentes de la novena edición del $D R A E$ (1843) y los diccionarios no académicos de Núñez de Taboada y Salvá ya que algunas de las voces de ambos diccionarios coinciden en la obra de Castro y Rossi (antagonismo, cinismo, civismo, conformista, coquetismo).

En el mismo prólogo se manifiesta otra de las características de este diccionario. Castro y Rossi pretende evitar la incorporación de galicismos y de neologismos que en algunas ocasiones no tienen ningún uso en la lengua común y se trata de voces puramente inventadas por algunos lexicógrafos como Domínguez. Las líneas siguientes del prólogo constituyen una crítica directa al diccionario de Domínguez (1853):

Y, por último se ha apartado de la manera de cierto diccionarista moderno, que deseoso de hacer una obra mas completa que la de la Academia, ha introducido en su libro voces francesas como castellanas, tales como ababrupto, y verbos estrambóticos sacados de nombres ó inventados por él, tales como abalandrar, aballenar, abarrilar, aballestarse, abaular, que, según él, significan tomar la forma del barco llamado balandra, la de la ballena, la de los barriles, la de las ballestas y la de los baules, con otros disparates del mismo género.

En efecto, las voces francesas que critica Castro y Rossi se encuentran en la nómina del Diccionario Nacional o Gran Diccionario Clásico de la Lengua Española de Domínguez (1853).

Finalmente, otro rasgo que caracteriza al tipo de voces de este diccionario es la inclusión de derivados técnicos y americanos. En este sentido, se ha calificado esta obra como la continuadora de la labor de Vicente Salvá (1846). ${ }^{26}$

\subsubsection{Incorporación de lemas en -ismo $e$-ista}

El corpus de voces derivadas con los sufijos -ismo e -ista en el diccionario de Castro y Rossi (1852) asciende a un total de 117, 27 en -ismo y 90 en -ista. Entre ellas conviene distinguir dos grupos. En primer lugar, los términos que este diccionario recoge de la tradición lexicográfica académica anterior a su obra, un total de 95 lemas. En segundo lugar, las adiciones propias de Castro y Rossi que no aparecen antes en ningún repertorio.

Las 95 voces del primer grupo se caracterizan por estar presentes en la novena edición del $D R A E$ (1843). Al igual que Salvá, una de las fuentes del diccionario de Castro y Rossi fue esta novena edición académica. Este tipo de términos pertenece a un léxico mayoritariamente técnico que corresponde a doctrinas religiosas y científicas y a sus respectivos partidarios (adanismo, calvinismo, apolinarista, catequista), a fenómenos científicos (asterismo, cataclismo) y, finalmente, a profesiones de distintos tipos bien artesanales (cancionista, citarista) o bien más técnicas (alimentista, botanista).

En el segundo grupo de voces, las adiciones propias del diccionario de Castro y Rossi, conviene distinguir dos conjuntos de derivados: por un lado, las voces propias en -ismo e-ista de

${ }^{26}$ Véase Baquero Mesa (1992: 458). 
este autor que se documentan en alguna edición del $D R A E$ del siglo XIX o del Xx y, por otro lado, los derivados con ambos sufijos que nunca llegan a aceptarse en el Diccionario académico.

Con respecto a los derivados que aparecen adicionados en alguna edición posterior del $D R A E$, un total de 11 términos del diccionario de Castro y Rossi cumplen esta condición, 4 en -ismo (algurismo, arabismo, arguarismo, carboranismo) y 7 en -ista (abolicionista, bolandista, bolsista, cantollanista, centralista, coalicionista y comunista). La fecha de incorporación de algunos de ellos no es muy lejana: arabismo se admite en la duodécima edición (1884) y bolsista en la undécima edición (1869). En cambio, en otros casos la distancia temporal es significativa como en el caso de cantollanista admitido en 1925 o coalicionista, voz incorporada en 1936.

A diferencia del grupo anterior de términos que llega a incorporarse en alguna edición del $D R A E$, un total de 11 voces del diccionario de Castro y Rossi no llega a admitirse en la obra académica. Algunas de estas voces son americanismos que se añaden por primera vez en este diccionario (caobista, caravanista). En otros casos se trata de términos jocosos que pertenecen a un léxico vulgar (carañuelista, cerdonismo) o bien de variantes de otras voces que están admitidas en el DRAE (cosmopolismo, variante de cosmopolitismo introducida en el DRAE en la edición de 1936). Finalmente, un reducido número de estas voces tiene la particularidad de pertenecer a un léxico técnico o científico demasiado específico (arminianismo, corolista). En definitiva, las características particulares de los términos del diccionario de Castro y Rossi que no se adicionan en el $D R A E$ justifican su ausencia en éste: voces demasiado específicas, vulgares o bien variantes de otras formas admitidas en el Diccionario académico. Junto a ello, debe relacionarse el criterio restrictivo de la Corporación ante la entrada de este tipo de voces pues no pertenecen al lenguaje común y, por este motivo, no deben incluirse en un diccionario usual de la lengua española.

\subsection{El DiCCIONARIO NACIONAL O GRAN DiCCIONARIO CLÁSICO DE LA LENGUA ESPAÑOLA DE Do- MÍNGUEZ (1853) $)^{27}$}

\subsubsection{Características generales}

Tras el éxito que alcanzó el Nuevo diccionario de la lengua castellana de Salvá (1846), el Diccionario nacional o gran diccionario clásico de la lengua española de Ramón Joaquín Domínguez es uno de los diccionarios no académicos más conocidos en la historia de la lexicografía del español del siglo XIX. Según los datos de Seco (1987: 156-157), esta obra se publicó por primera vez en dos tomos en los años 1846 y 1847. La notable difusión de este repertorio se observa en las diecisiete reimpresiones que se distribuyeron en un breve espacio de cuarenta años. A pesar de la escasa atención que ha recibido ${ }^{28}$ «es quizá el diccionario de nuestra lengua que más ediciones ha alcanzado, después del de la Academia: diecisiete en poco más de cuarenta años; la última, de 1889» (Seco 1987: 157).

Las características que presenta el Diccionario nacional justifican el éxito que alcanzó: la adición de un gran número de voces y, en segundo lugar, su carácter enciclopédico. Ambos

${ }^{27}$ La edición que se ha usado en este trabajo es la que figura en el NTLLE que no corresponde a la primera edición de 1846-1847.

${ }^{28}$ Los estudios encontrados sobre este diccionario -Seco (1987), Azorín (2000), García Platero (2003)- destacan características generales de la obra de Domínguez pero no describen con detalle la tipología de voces y el tratamiento que reciben estos términos en el diccionario. Recientemente se ha realizado un trabajo de investigación elaborado por Sandra Iglesia (2002), Las voces de la química en el Diccionario Nacional de R. J. Domínguez, que estudia con profundidad el léxico científico y técnico en este diccionario. 
rasgos se presentan como una gran novedad en la portada de este repertorio: «el más completo de los léxicos publicados hasta el día». En el prólogo del diccionario el autor explica con más detalles ambos objetivos:

El que tengo el honor de presentar al público, es sin disputa, sino [sic] perfecto, el mas completo de cuantos se han publicado [...]. El Diccionario Nacional se encuentran $1^{\circ}$ las voces antiguas con las diversas acepciones en que las usaron nuestros mayores, sin omitir las que el uso ha conservado; $2^{\circ}$ todas las modernas autorizadas por este, con las diferentes acepciones en que estén admitidas; $3^{\circ}$ cuatro mil y quinientas voces del lenguaje usual, que no se hallan en el Diccionario de la Academia; $4^{\circ}$ cien mil y quinientas voces técnicas de diferentes ciencias y artes; $5^{\circ}$ los nombres y situación de las principales ciudades del mundo, con las villas, aldeas, ríos, etc. De España; $6^{\circ}$ los nombres de los hombres mas notables del universo, desde la existencia de este y que pertenecen a la historia; y por último, todo aquello que puede interesar al hombre estudioso. (Prólogo del autor, página 1)

Como se puede observar en el fragmento anterior, el deseo «totalizador» (Azorín 2000) de presentar una nómina de voces va acompañado de otro gran propósito: la descalificación hacia el repertorio académico. El diccionario de Domínguez es uno de los más críticos hacia la Corporación. ${ }^{29}$ Esta realidad ya se ha observado en los lexicógrafos anteriores, Núñez de Taboada y Salvá, pero en esta obra esta característica se acentúa.

Todo ello, la superación del caudal léxico frente al diccionario de la Academia y la tendencia al enciclopedismo, tiene su origen en el diccionario francés de Bescherelle, Dictionnaire national ou grand dictionnaire critique de la langue française, publicado unos años antes en 1843. Esta obra se enmarca en la técnica lexicográfica francesa del siglo XIX de elaborar diccionarios de «grand format, on note en fin l'apparition d'un nouveau type de répertoires, plus abordables, plus facilement consultables, les dictionaires dits "portatifs" ou "de poche"» (Bray 1990: 1802). Del mismo modo que los diccionarios franceses anteriores de Boiste (1800) y Nodier (1836) el diccionario de Bescherelle tuvo una gran difusión y se publicaron un total de 9 ediciones. $^{30}$

A diferencia de los lexicógrafos anteriores, Domínguez tuvo un contacto directo con la lexicografía francesa; cabe precisar la redacción en los mismos años del Diccionario nacional de otra obra: el Diccionario universal francés-español y español-francés. De acuerdo con Azorín (2000) y Seco (1987) las similitudes de la obra de Domínguez con la de Bescherelle son varias. Por un lado, existen cuestiones formales semejantes como el título de la obra -aparecen los adjetivos nacional y gran-, la presencia del mismo grabado en la portada que el diccionario francés ${ }^{31}$ o la masiva inclusión de voces técnicas, de nombres de ciudades y de personajes históricos. Por otro lado, se observa una gran igualdad en las definiciones de los lemas. En el si-

${ }^{29}$ El subjetivismo en el diccionario de Domínguez es uno de los rasgos más comentados y señalados de su quehacer lexicográfico. En el contenido de las definiciones subyace su ideología. Seco (1987), Esparza (1999) e Iglesia (2002) se centran en el estudio de las definiciones subjetivas de Domínguez.

${ }^{30}$ Bray (1990: 1804) proporciona las siguientes fechas para las nueve ediciones: $2^{\mathrm{a}}$ edición en $1845-1846,3^{\mathrm{a}}$ en $1849,4^{a}$ en $1851,5^{a}$ en $1852,6^{a}$ en $1853,7^{a}$ en 1858 y $9^{a}$ en 1861 . Para observar la influencia de este diccionario en los diccionarios no académicos de Domínguez y Gaspar y Roig, en esta investigación se ha consultado la cuarta edición que figura en la página web http://www.gallica.bnf.fr/ con la fecha de 1846.

${ }^{31}$ Seco (1987: 161) describe el grabado que copia Domínguez del diccionario de Bescherelle: «un libro abierto sobre un fondo de nubes oscuras, detrás de las cuales surge un sol radiante». 
guiente apartado de este estudio se presenta la traducción literal al español de las definiciones de Bescherelle para algunos lemas en -ismo e -ista del diccionario de Domínguez. Por lo tanto, la tendencia al enciclopedismo que inaugura Domínguez caracterizada por un "prurito acumulador» (Seco 1987: 160) ya estaba presente en Bescherelle y Domínguez la toma como ejemplo en la preparación de su diccionario.

Finalmente, otra de las justificaciones del éxito que alcanzó el diccionario de Domínguez se explica por la novedad que supuso desde el punto de vista comercial. La aparición de este nuevo género lexicográfico en España, el diccionario enciclopédico, se ofrecía, como muy bien argumenta Azorín (1996-1997: 120),

como instrumento polivalente, compendio de todos los saberes -incluido el idiomático-y, por lo tanto, sustituto de otros compendios más especializados-incluido el diccionario de la lengua-. Ese hibridismo que a los lectores más exigentes podía repugnar, ha constituido, al parecer, la clave del éxito de estas obras cuya utilidad es, por otro lado, incontestable.

\subsubsection{Incorporación de lemas en-ismo $e$-ista}

Los derivados en -ismo e -ista que figuran en el diccionario de Domínguez superan el número de incorporaciones con ambos sufijos hasta la novena edición (1843) del Diccionario académico. El Diccionario nacional presenta alrededor de 711 voces más que la novena edición del $D R A E$ con estos sufijos. La diferencia es considerable y como se ha señalado anteriormente en la caracterización del diccionario de Domínguez, el mayor número de este tipo de léxico responde al carácter enciclopédico propio de esta obra. Esta característica representa un cambio de enfoque en la técnica lexicográfica de los diccionarios no académicos publicados a partir de la década de los años cincuenta que no se ha observado en los diccionarios anteriores del primer cuarto del siglo XIX. Con el fin de observar esta diferencia, en la siguiente tabla se presenta el número de derivados en -ismo e -ista introducidos en los diccionarios de Núñez de Taboada, Salvá, Castro y Rossi y Domínguez:

\begin{tabular}{|c|c|c|c|c|}
\hline DICCIONARIO & $\begin{array}{c}\text { NÚÑEZ DE TABOADA } \\
(1825)\end{array}$ & $\begin{array}{c}\text { SALVÁ } \\
(1846)\end{array}$ & $\begin{array}{c}\text { CASTRO Y ROSSI } \\
(1852)\end{array}$ & $\begin{array}{c}\text { DOMÍNGUEZ } \\
(1853)\end{array}$ \\
\hline $\begin{array}{l}\mathrm{N}^{\circ} \text { de derivados en -ismo } \\
\mathrm{e}-i s t a\end{array}$ & 54 & 96 & 117 & 711 \\
\hline
\end{tabular}

TABLA 1. Número de derivados en-ismo $e$-ista incorporados en los diccionarios no académicos de la primera mitad del siglo XIX

El gran cambio que se observa en la obra de Domínguez responde a la voluntad acumuladora característica del género enciclopédico que adopta este autor para la elaboración de su obra. La elevada cantidad de 711 voces con ambos sufijos es el reflejo de la pretensión de reunir el máximo número posible de términos con el objetivo de acumular todos los conceptos existentes. Esta característica constituye una novedad en la lexicografía española del siglo XIX que Domínguez lleva a la práctica con el Diccionario nacional. El alto número de derivados que se ha presentado en la tabla anterior permite considerar al diccionario de Domínguez la primera obra española que se engloba en este nuevo género lexicográfico.

En el conjunto de los 711 términos en -ismo e -ista del diccionario de Domínguez deben diferenciarse distintos grupos de palabras en función de su aparición o de su ausencia en 
el Diccionario académico en ediciones anteriores o bien en ediciones posteriores a la obra de Domínguez. Los resultados obtenidos tras el cotejo de los lemas del diccionario de Domínguez con el $D R A E$ o con otros diccionarios no académicos han sido los siguientes que se presentan en la tabla 2:

\begin{tabular}{|c|c|}
\hline $\begin{array}{c}\mathrm{N}^{\mathrm{o}} \text { DE INCORPORACIONES EN }- \text { ISMO E }- \text { ISTA } \\
\text { (TOTAL: 711 VOCES) }\end{array}$ & OBRA LEXICOGRÁFICA \\
\hline 196 & DRAE del siglo XIX y XX \\
\hline 418 & Sólo en los diccionarios no académicos \\
\hline 53 & Otros diccionarios no académicos \\
\hline 44 & $\begin{array}{c}\text { Ediciones del } D R A E \text { anteriores al } \\
\text { diccionario de Domínguez }\end{array}$ \\
\hline
\end{tabular}

TABLA 2. Distribución de los derivados en -ismo e-ista recogidos en el Diccionario de Domínguez, en el DRAE o en otros diccionarios no académicos

En el primer grupo de voces, las que se incorporan posteriormente en el $D R A E$ hay que destacar la modernidad del diccionario de Domínguez por introducir con una fecha temprana un mayor número de voces en -ismo e-ista. Al igual que se ha observado en los anteriores diccionarios no académicos, un total de 96 lemas en -ismo e -ista se añaden en las tres ediciones finales del siglo XIX: 34 en la undécima (1869), ${ }^{32} 37$ en la duodécima (1884) ${ }^{33}$ y 25 en la decimotercera (1899). ${ }^{34}$ Desde el punto de vista formal, estos derivados pertenecen al lenguaje científico y técnico y al lenguaje común. En el siglo xx, el $D R A E$ incorpora el resto de voces procedentes del diccionario de Domínguez: 23 en 1925, 12 en 1936, 2 en 1947, 5 en 1956, 4 en 1970, 2 en 1984 y 5 en 1992. Además, 47 voces aparecen adicionadas en el Diccionario manual de la Academia y no llegan a aceptarse en el Diccionario usual.

El segundo grupo de 418 voces descrito en la tabla 2, las que la Academia no incorpora en ninguna de sus ediciones, es el más interesante desde el punto de vista lexicográfico. Se trata un conjunto de voces que ha existido en la historia lexicográfica del español pero que nunca ha alcanzado un valor normativo. De ellas, 129 aparecen exclusivamente en el diccionario de Domínguez y el resto, 289, se documenta posteriormente en algún otro diccionario no académico como el de la editorial Gaspar y Roig (1853) o el de Zerolo (1895). Particularmente, en este conjunto de voces se observa la actitud de ampliar la nomenclatura que adopta Domínguez (Esparza 1999: 57), esto es, pretende superar el caudal del $D R A E$ y registrar una mayor cantidad de voces pertenecientes al vocabulario científico y técnico. Según Esparza (1999: 56) en esta actitud de Domínguez «late la fascinación por el progreso, que desplaza objetos y crea otros nuevos, provoca préstamos de otras lenguas y la creación de nuevas voces».

Los 418 términos que no han formado parte de ninguna edición del $D R A E$ se han clasificado en cinco grupos en función de la definición que aparece en el diccionario de Domínguez: voces antiguas, doctrinas de otros países que fueron poco conocidas en España, derivados técnicos, variantes formales y, finalmente, voces jocosas.

\footnotetext{
${ }^{32}$ Algunos ejemplos de voces son: dualista, eclecticismo, utopista.

${ }^{33}$ Algunos ejemplos son: kantismo, lazarista, platonismo.

${ }^{34}$ Algunos ejemplos son: bonapartista, neptunista, vulcanismo.
} 
En primer lugar, las voces antiguas se refieren a doctrinas religiosas, a los partidarios de ellas y a profesiones que se remontan a la época griega o a siglos posteriores que ya no tienen un uso en la lengua común del siglo XIX (acrocorismo, eudista, lanista, radamista, superista):

Acrocorismo: Ejercicio de los miembros. || Danza de los antiguos en que agitaban frecuentemente las piernas y los brazos.

Eudista: Religioso agustino que añadía a los tres votos de ordenanza, el de consagrarse a la instrucción de las pecadoras arrepentidas.

En algunas ocasiones las bases léxicas de estos derivados son nombres propios de la época clásica (osianista, papinianista, swedenborgismo):

Papianista: Jurisconsulto que sigue las doctrinas de Papiniano. (Roma, año 140).

Las voces que se han clasificado en el segundo grupo en general se refieren a doctrinas y a los partidarios de ellas procedentes de otros países europeos u orientales (gluquista, ludista, utraquista) cuyas teorías probablemente fueron poco conocidas y no llegaron a penetrar en España. La ausencia de testimonios escritos en el CORDE y en el Corpus del Español indica que estas voces no tuvieron un uso extendido en la lengua española. A continuación se presenta algún ejemplo en el que se puede observar que se trata de términos que se relacionan con alguna doctrina de algún país europeo:

Ludista: Nombre y epíteto dado a los promovedores de una revolución popular que sucedió en Inglaterra a principios del siglo XIX, y cuyo objeto era destruir las máquinas, sopretesto de que estas invenciones son perjudiciales a los operarios o jornaleros. Úsase también como adjetivo para calificar todo lo perteneciente, relativo o análogo al partido o sistema indicado.

En el conjunto de voces técnicas, destaca la especificidad de su significado puesto que son términos muy concretos de disciplinas científicas. Estas voces técnicas, en total se ha encontrado aproximadamente 170, están formadas generalmente por raíces griegas cultas que forman numerosos sustantivos en -ismo que designan fenómenos científicos y médicos (catartismo, diclinismo, hipnalismo, hipnolismo, hipospatismo, zoomagnetismo) o bien, doctrinas científicas, filosóficas (antidualismo, metalantroponismo, owenismo), políticas (balancismo, inconstitucionalismo, owenismo) y religiosas (antropoteismo, arnaldismo, misionarismo). A continuación se presenta la definición de algunas de estas voces en las que se puede observar el contenido específico de su significado:

Catartismo: Coaptación o reducción de un hueso dislocado.

Metalantroponismo: Una de las tres formas o aspectos principales del antropomagnetismo.

Balancismo: Sistema del equilibrio social

Misionarismo: Celo por la propagación de la fe

Los derivados técnicos en -ista, por su parte, nombran a los seguidores de las doctrinas científicas y religiosas (atraccionista, animaculista, antifilosofista, ovarista): 
Atraccionista: Partidario del sistema de Newton.

Animalculista: Partidario del animalculismo: fisiólogo que explica el fenómeno de la generación por los animalillos espermáticos.

Un grupo numeroso de unos 35 lemas son profesiones muy específicas del campo de la ciencia y la medicina (conchiliologista, epigenesista, himenotomista, nomologista, oftalmonosolojista, zoófitologista):

Conchiliologista: El naturalista inteligente en conchiliología, o particularmente dedicado á estudios conchiliológicos.

Himenotomista: Persona especializada en la disección de las membranas

Entre estas voces técnicas se distingue una agrupación de 23 palabras en -ismo e -ista que los diccionarios enciclopédicos posteriores de Gaspar y Roig (1853) y Zerolo (1895) también incorporan. Estos términos son específicos porque pertenecen a los campos de la botánica y la zoología y denominan géneros de animales y plantas (anoplista, basanista, calista, egialista, platanista, ranista):

Anoplista: Entom. Sub-género de coleópteros pentámero esternoxos.

Basanista: Zool. Género de crustáceos.

Egialista: Bot. Arbusto de la Nueva-Holanda, que forma un género de plumbagíneas.

Otro grupo representativo y que también está presente en los anteriores diccionarios no académicos es el de las variantes formales de otras voces que han sido aprobadas en el $D R A E$ con otros sufijos. Nuevamente, el carácter enciclopédico del diccionario de Domínguez explica la aparición de las 45 variantes encontradas. En concreto, se han observado dos tipos de variantes.

En primer lugar, aquellas que en el $D R A E$ aparecen con otro sufijo, generalmente -ano, -ario, -ero, -ico, -ogo en lugar del sufijo -ista. Así, los derivados hidraulista, ictiologista, islamista, odontologista se han aprobado respectivamente con otras formas derivativas en el DRAE: hidráulico, ictiólogo, mahometano, odontólogo. En algunos casos, las variantes con otros sufijos existen en textos escritos y se documentan en el $D R A E$ con una fecha anterior al siglo XIX. Así, hidráulico se adiciona en la primera edición del $D R A E$ (1780) y mahometano ya figura en el Diccionario de Autoridades. En cambio, en otros casos la variante con otro sufijo es posterior al terminado en -ista: la voz odontólogo se incorpora en la decimotercera edición (1899) y el derivado ictiólogo aparece en la decimocuarta edición (1914). Las documentaciones de ictiólogo y odontólogo en el CORDE no son anteriores al siglo XIX. Una posible interpretación de estos datos permite apuntar que ambos neologismos en con el sufijo -ogo no tuvieron un uso extendido hasta el siglo $\mathrm{xx}$, como indican los testimonios escritos del CORDE. Además, el sufijo -ista no se difundió en estos derivados en el siglo XX a pesar de estar documentados un siglo antes en el diccionario de Domínguez. La presencia de este sufijo en estas voces se relaciona con la influencia de la lexicografía francesa. En la lengua francesa ambos derivados se han formado con el sufijo -iste, ichthyologiste y odontologiste, y se documentan en siglo XIX en los diccionarios de Boiste (1829) y Bescherelle (1843). Esta influencia francesa explica la presencia de estas formas españolas en -ista en el diccionario de Domínguez. 
En el segundo tipo de variantes se encuentran voces que presentan una variación gráfica en su forma; esto es, en el $D R A E$ aparecen con el mismo sufijo pero con otras grafías. A modo de ejemplo, los lemas arborista y caraitismo del diccionario de Domínguez corresponden a las formas arbolista y caraísmo del DRAE. La primera de ellas, arbolista, existe en el diccionario oficial desde Autoridades y la segunda, caraísmo, se añade en la decimoquinta edición (1925). Este lema, por lo tanto, existe desde prácticamente un siglo antes ${ }^{35}$ en el diccionario de Domínguez y su documentación en este diccionario se relaciona con la presencia de esta voz en el diccionario de Bescherelle (1843). No obstante, en el diccionario de Domínguez se encuentran las cuatro formas: arbolista-arborista y caraísmo-caraitismo. Desde el punto de vista semántico, a pesar de tener variaciones formales los lemas del diccionario de Domínguez tienen el mismo significado que los del $D R A E$; la diferencia radica en las variaciones formales del lema. El único propósito de su aparición en este diccionario no académico responde a la intención de superar la nómina del repertorio académico.

Finalmente, el grupo de voces coloquiales o jocosas es el más minoritario; sólo se han encontrado tres términos con alguno de los sufijos -ismo o -ista (poltronerismo, trompista y sicofantismo).

Una gran parte de las voces caracterizadas en los cinco grupos no se recoge en ningún corpus de voces del español. Como ya se ha comprobado en algunos ejemplos anteriores, la ausencia de estos términos en el $D R A E$, en el CORDE y en otros corpus electrónicos como el Corpus del Español induce a preguntarnos el motivo de su única existencia en el diccionario de Domínguez. Tras la indagación de estas voces en repertorios electrónicos de lexicografía francesa se ha encontrado una gran similitud. En efecto, como ya han apuntado algunos investigadores (Azorín 1996, 2000, Seco 1987, Esparza 1999) la deuda de Domínguez a los repertorios de Bescherelle y Boiste es indudable. Para comprobar la influencia de la lexicografía francesa en el diccionario de Domínguez se han seleccionado 200 términos de los 418 lemas de esta obra que no aparecen en el $D R A E$. Estos 200 lemas del diccionario de Domínguez se han consultado, en su correspondiente forma en la lengua francesa, en la versión en CD del Trésor de la Langue Française Informatisé y en la versión electrónica del diccionario de Bescherelle (http://www.gallica.bnf.fr/) y aproximadamente 100 lemas en -ismo e-ista se encuentran en textos escritos franceses de los siglos XVIII y XIX y en los diccionarios de Boiste y Bescherelle. De acuerdo con estos datos la tendencia al enciclopedismo de Domínguez procede de estos dos diccionarios enciclopédicos franceses y el uso de estas voces se encuentra en textos escritos procedentes de autores como Balzac, Flaubert, O’Neddy o Sainte-Beuve.

En la siguiente tabla 3 se refleja la similitud de las definiciones entre el diccionario de Bescherelle y el de Domínguez. Claramente se puede observar que el lexicógrafo español conocía con profundidad las obras de los autores franceses como se aprecia en la copia de algunas definiciones:

\begin{tabular}{|c|c|c|}
\hline LEMA & BESCHERELLE & DOMÍNGUEZ \\
\hline actenista & $\begin{array}{l}\text { (ét., V. Actène). Entom. Genre de } \\
\text { coléoptères malacodernes, ayant pour } \\
\text { type l'acténiste aux ailes noires de } \\
\text { Cayenne }\end{array}$ & $\begin{array}{l}\text { Entom. Género de insectos } \\
\text { malacodermos de Cayena. }\end{array}$ \\
\hline anoplista & 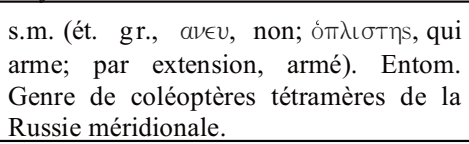 & $\begin{array}{l}\text { s.m. Entom. Género de } \\
\text { coleópteros tetrámeros de Rusia. }\end{array}$ \\
\hline
\end{tabular}

${ }^{35}$ A finales del siglo XIX este lema se encuentra documentado en el CORDE en la obra Historia de los heterodoxos españoles de 1880 de Marcelino Menéndez Pelayo. 


\begin{tabular}{|c|c|c|}
\hline astolismo & 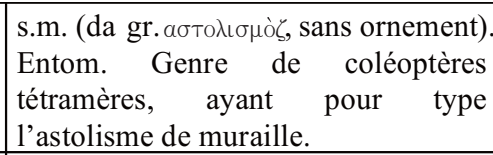 & $\begin{array}{l}\text { s.m. Entom. Género de } \\
\text { coleópteros tetrámeros. }\end{array}$ \\
\hline barbitista & $\begin{array}{l}\text { du gr. ßapoıtí̧ } \omega \text {, je joue du lutl.; par } \\
\text { allusion à la stridulation que produisent } \\
\text { les insects appelés de ce nom). Entom. } \\
\text { Genre de la familla des locustiens, ayant } \\
\text { pour espéces principales le barbitiste } \\
\text { automnal et le barbitiste serricaude de la } \\
\text { France et de l'Europe méridionale. }\end{array}$ & Crust. Género de langostas \\
\hline fenelonista & $\begin{array}{l}\text { Partisan de la doctrine de Fénelon, } \\
\text { du quiétisme. }\end{array}$ & $\begin{array}{l}\text { Nombre que se da a los } \\
\text { partidarios de Fenelón, conocido } \\
\text { también con el de quietista. }\end{array}$ \\
\hline helmintologista & $\begin{array}{l}\text { Didact. Naturaliste qui s'occupe } \\
\text { spécialment des vers. }\end{array}$ & $\begin{array}{l}\text { V. helmintólogo. (El naturista } \\
\text { que se dedica especialmente al } \\
\text { conocimiento ó estudio de la } \\
\text { heomintología). }\end{array}$ \\
\hline merismo & $\begin{array}{l}\text { Littér. Figure de rhétorique; c'est la } \\
\text { división d'un sujet, d'un point à } \\
\text { traiter, et ses diferentes parties. I } \\
\text { Bot. Genre de la famille des } \\
\text { champignons, intermédiaire entre les } \\
\text { genres théléphore et clavaire. Ces } \\
\text { champignons sont rameux, coraices, } \\
\text { comprimés, et le plus souvent poilus } \\
\text { à leur sommet. Mérisme fastidieux, } \\
\text { vermiculaire, créete, palmé. }\end{array}$ & $\begin{array}{l}\text { La división de un asunto o } \\
\text { argumento en sus diferentes } \\
\text { partes o secciones. } \| \text { Bot. Género } \\
\text { de hongos. }\end{array}$ \\
\hline oligista & $\begin{array}{l}\text { Min. Se dit d'une variété de fer qui } \\
\text { ne laisse à faire pour le rendre } \\
\text { ductile que de le dépouiller de son } \\
\text { oxygène. Le fer oligiste est rarement } \\
\text { pur; il est presque toujours } \\
\text { accompagné de fer oxydé-rouge } \\
\text { compacte plus ou moins melange de } \\
\text { terre, qui en diminue sa richesse. }\end{array}$ & $\begin{array}{l}\text { Variedad de hierro, que se hace } \\
\text { dúctil quitándole el oxígeno. }\end{array}$ \\
\hline unionista & $\begin{array}{l}\text { S'est dit des membres de } \\
\text { l'opposition, en Belgique, avant } \\
\text { 1830. Les unionistes avaient opéré } \\
\text { une fusion de l'opposition catholique } \\
\text { et aristocratique avec l'opposition } \\
\text { philosophique et democratique dite } \\
\text { libérale. }\end{array}$ & $\begin{array}{l}\text { Nombre que recibieron en } \\
\text { Bélgica los miembros de la } \\
\text { oposición antes de } 1830 \text { porque } \\
\text { se había verificado una fusión de } \\
\text { la oposición católica y } \\
\text { aristocrática con la oposición } \\
\text { filosófica y democrática llamada } \\
\text { liberal }\end{array}$ \\
\hline urbanista & $\begin{array}{l}\text { Membre d'une congrégation de } \\
\text { femmes instituée par le pape Urbain. } \\
\text { Les urbanistes suivaient la règle de } \\
\text { Sainte-Claire. II Nom de sectaires } \\
\text { opposés à Clement VII. }\end{array}$ & $\begin{array}{l}\text { Religiosa de una congregación } \\
\text { de mujeres, fundada por el papa } \\
\text { Urbano. \| Nombre de los } \\
\text { sectarios opuestos á Clemente } \\
\text { IV. }\end{array}$ \\
\hline
\end{tabular}


En la tabla 3 puede observarse que en algunos casos (helmintologista, unionista, urbanista) la definición es una traducción exacta al español del diccionario francés. En cambio, en otras definiciones se ha modificado la redacción original y no es tan enciclopédica como la que figura en el diccionario francés (barbitista, merismo). De todos modos, la comparación de las definiciones de la tabla 3 demuestra la gran influencia de la lexicografía francesa en el diccionario de Domínguez. Además, la existencia de estos términos en el Trésor de la Langue Française Informatisé evidencia su predominio en la lengua francesa. De este modo, el lexicógrafo español se basó en estas fuentes sin contrastar su uso en la lengua española y se guió simplemente por la tendencia al enciclopedismo de las obras francesas.

El tercer grupo de voces descrito en la tabla 2 se relaciona con las fuentes de la obra de Domínguez. Se trata de voces en -ismo e -ista que aparecen con anterioridad en otros repertorios no académicos y que no se han llegado a incorporar en el $D R A E$. En líneas generales, se trata de léxico científico y técnico o de variantes de otros lemas procedentes del diccionario de Terreros, un total de 18 lemas (figurista, egloguista, litotomista), o de los diccionarios anteriores de Núñez de Taboada (1825), Salvá (1846) o Castro y Rossi (1852) (ovarismo, cabriolista, chabacanismo). En estas voces también cabe destacar la influencia de la lexicografía francesa pues algunas de ellas (figurista, litotomista) se documentan en textos franceses del siglo XIX del Trésor de la Langue Française Informatisé.

Finalmente, el último conjunto de 44 voces se caracteriza por estar presente en la novena edición (1843) del DRAE. Estas voces tienen una historia anterior y existen en el Diccionario académico desde su primera incorporación en el Diccionario de Autoridades o en las ediciones en un tomo de finales del siglo XVIII y principios del siglo XIX (abismo, literalista, panegirista, reumatismo, trapacista). Estos derivados aparecen con el mismo significado en la posterior introducción en el diccionario de Domínguez. A continuación se muestra un ejemplo en el que se observa que ambas definiciones responden al mismo significado del lema trapacista:

\section{Trapacista}

Embustero, engañador en las compras, ventas ò cambios ( $D A-1739)$.

Adj. Embustero, engañador, embaucador en las compras, ventas ó cambios.|| El que con astucias, falsedades y engaños ó mentiras procura engañar á otro en cualquier asunto (Domínguez 1853).

Como se ha indicado con detalle en la caracterización de los derivados en -ismo e -ista del diccionario de Domínguez este autor tiene como referencia tres grandes fuentes: ${ }^{36}$ en primer lugar, la tradición de los diccionarios no académicos anteriores de Terreros, Núñez de Taboada, Salvá y Castro y Rossi con los que comparte algunas voces; en segundo lugar, las ediciones del $D R A E$ anteriores a su diccionario y, la última y la más importante la lexicografía francesa del siglo XIX. La mayoría del material nuevo en -ismo e -ista que aporta este autor en su obra se debe a la recopilación de estas voces en los diccionarios de Boiste (1834) y Bescherelle (1843).

De estas tres fuentes recoge sobre todo voces técnicas y científicas en -ismo e -ista que en algunos casos se incorporan en posteriores ediciones del $D R A E$ de los siglos XIX o xx y en

${ }^{36}$ Estas tres fuentes coinciden con las que Iglesia (2002) presenta en su trabajo de investigación en el que dedica un apartado al estudio de las fuentes de este diccionario. 
otros no llegan a obtener un carácter normativo precisamente por la especificidad de su significado. De esta manera, la ausencia de un gran número de voces de este lexicógrafo en el Diccionario académico viene a confirmar una distinta concepción frente a los tecnicismos en ambas tradiciones lexicográficas, «un auténtico conflicto de paradigmas» en palabras de Esparza (1999: 50).

En definitiva, el contacto con las obras francesas permitió la incorporación masiva de un gran número de voces desconocidas hasta entonces en el léxico del español. Sin ninguna duda, las aportaciones de Domínguez junto con las del resto de lexicógrafos no académicos contribuyeron a un enriquecimiento del vocabulario español y marcaron además un cambio en la técnica lexicográfica española: «la extensión del diccionario hacia la enciclopedia» (Esparza 1999: 58), esto es, el nacimiento del género del diccionario enciclopédico. Esta nueva tendencia se desarrolla en los diccionarios no académicos de los autores posteriores del siglo XIX y del XX.

\subsection{DiCCIONARIO ENCICLOPÉDICO DE La LENGUA ESPAÑOLA DE GASPAR Y RoIG (1853)}

\subsubsection{Características generales}

El nuevo modelo de diccionario enciclopédico inaugurado en España por R. J. Domínguez en 1843 es seguido inmediatamente por otros lexicógrafos. El Diccionario enciclopédico de la lengua española, con todas las vozes, frases, refranes y locuciones usadas en España y las Américas Españolas [...] publicado por la editorial Gaspar y Roig es el segundo diccionario en aparecer a partir de esta nueva tendencia lexicográfica. En el título de esta obra aparece el adjetivo enciclopédico que evidencia la nueva técnica lexicográfica empleada en su elaboración. Esta referencia explícita en el título del diccionario lleva a considerarlo como el primer diccionario que manifiesta la adhesión a este género lexicográfico (Bueno Morales 1996, García Platero 2003).

Desde el punto de vista formal, esta obra es semejante al Diccionario nacional de Domínguez. En él predomina el carácter enciclopédico, anunciado en el título de la obra, que puede observarse en la portada del diccionario como si de un eslogan publicitario se tratase: «Es el lenguaje común antiguo y moderno, las de ciencias, artes y oficios, las notables de historia, biografía, mitología y geografía universal y todas las particularidades de las provincias españolas y americanas».

El conjunto de esta obra se presentó en dos volúmenes publicados en fechas distintas: el primero en 1853 y el segundo en 1855 . El éxito de esta obra fue considerable al igual que el diccionario de Domínguez; las numerosas reimpresiones que se realizaron de este diccionario hasta finales del siglo XIX atestiguan su extensiva difusión. ${ }^{37}$

Una de las novedades que aporta esta obra es una nueva forma de elaboración «la denominada en equipo, con un director responsable al frente de la redacción» (Bueno Morales 1996: 154). En el prólogo del primer tomo se puede observar que el director es Eduardo Chao. Según Bueno Morales 1996 y García Platero 2003, en el siguiente tomo no aparece el nombre del responsable y en las posteriores reimpresiones el director fue Nemesio Fernández. La pretensión de abarcar el léxico de todos los campos posibles del saber es uno de los motivos de

\footnotetext{
${ }^{37}$ Bueno Morales (1996: 153-154) enumera catorce reimpresiones de la primera publicación en los años 18531855: 1858, 1862, 1854, 1864-67, 1865, 1870, 1872, 1872-75, 1875, 1875-78, 1878, 1878-82, 1884 y 1885.
} 
trabajar en equipo y compartir la autoría como argumenta García Platero (2003: 272): «se trabaja con datos de muy variada procedencia, de ahí que se requiera la participación de un grupo de personas convenientemente organizadas».

En el prólogo de Eduardo Chao de la primera edición se manifiesta el criterio abarcador de la admisión de voces técnicas propio de la tendencia no académica y, además, se reconoce explícitamente la influencia de la lexicografía francesa de Boiste y Bescherelle: «un sentimiento de justicia y de conveniencia pública, que expresa muy bien Bescherelle, nos ha decidido a favor de un DICCIONARIO ENCICLOPÉDICO».

Finalmente, otra de las características propias de este diccionario es la búsqueda de una mayor objetividad, a diferencia del diccionario de Domínguez. Como sugiere Bueno Morales (1996: 157):

La filosofía que preside la redacción del Diccionario enciclopédico es cumplir con una de las principales funciones que debe tener todo producto lexicográfico que se precie, su función social y didáctica. De ahí la objetividad en las definiciones.

\subsubsection{Incorporación de lemas en-ismo $e$-ista}

La técnica lexicográfica del Diccionario enciclopédico de la editorial Gaspar y Roig, basada en la incorporación masiva de voces en su nomenclatura procedente de todas las ramas del saber, explica la presencia de aproximadamente 1088 términos derivados con ambos sufijos.

Este conjunto de derivados tiene tres procedencias distintas. En primer lugar, 113 lemas de la obra de la editorial Gaspar y Roig se adicionan en alguna edición posterior del $D R A E$. En segundo lugar, unos 194 términos únicamente aparecen en esta obra no académica y no se incorporan en ninguna edición del Diccionario académico y, finalmente, 781 voces aparecen con anterioridad en otros repertorios lexicográficos: en el $D R A E$ de los siglos XVIII y XIX y en los diccionarios no académicos anteriores.

En el primer grupo de términos, los añadidos posteriormente en el $D R A E, 79$ se incorporan en las tres últimas ediciones del siglo XIX (29 en 1869, 29 en 1884 y 21 en 1899) y 34 en las ediciones del siglo Xx (5 en 1914, 7 en 1925, 3 en 1936, 1 en 1956, 2 en 1970, 2 en 1992 y finalmente, 10 en el Diccionario manual de 1927 o de 1984 y 4 en el Diccionario histórico del $D R A E$ ). En general estas voces son doctrinas científicas (automatismo, dinamismo), filosóficas (antropomorfismo, determinismo) y religiosas (dogmatismo, fetichismo).

Entre las 194 voces que no llegan a incorporarse en el Diccionario académico se vuelve a repetir la misma clase de voces que se ha comentado en el diccionario anterior de Domínguez. Entre este tipo de términos destaca un conjunto de 47 derivados técnicos en -ismo e -ista de la historia de la ciencia, la medicina, la filosofía (esfecismo, lollardismo, odontismo) y también de la esfera de las profesiones (litrocromista, ${ }^{38}$ orictolojista) cuya presencia se relaciona con el «afán de grandiosidad» (Bueno Morales 1996: 155) que preside la redacción de esta obra:

${ }^{38}$ Esta voz aparece lematizada de este modo en el NTLLE pero en el interior del diccionario de Gaspar y Roig se puede comprobar que aparece litocromista, sin la primera $r$. Se trata de un error del NTLLE', porque este término no se recoge por primera vez en el diccionario de Gaspart y Roig sino que se adiciona con anterioridad en el diccionario de Domínguez (1853). 
odontismo: Hist. ant.: canto griego ejecutado en la flauta, en un tono muy agudo. orictolojista: Sinón. de mineralojista.

En este diccionario también resultan representativas las voces científicas específicas de los campos de la botánica y la zoología que definen tipos de plantas y de especies de animales (fonaspista, gnorista, lerista, sialista):

fonaspista: Zool.: se dice de una serpiente que tiene veneno.- adj. s. pl.: grupo de reptiles ofidios aspistos, que comprende los que tienen todos los dientes venenosos en la mandíbula superior.

En un segundo grupo se encuentra un total de 29 derivados que corresponde en su mayoría a doctrinas y a sus partidarios o bien, a conceptos pertenecientes a épocas antiguas que probablemente no eran conocidos ni muy frecuentes en la lengua de mediados del siglo XIX (arrabonista, hipaspista, rasorista, sivaísta, swedemborgista):

swedemborgista: Discípulo de Swedemborg. Los Swedemborgistas forman una iglesia aparte que llaman Nueva Jerusalén, y se hallan diseminados en Suecia, Alemania, Inglaterra y los Estados Unidos.

La inexistencia de testimonios escritos en el CORDE para estos términos reafirma la idea de que se trate de voces que no tuvieron una gran difusión en la lengua escrita española.

Finalmente, otro grupo de unos 17 derivados (dialogista, orictologista) se caracteriza por ser variantes de otros lemas que están aprobados en el $D R A E$ con otras bases léxicas (dialoguista, mineralogista). Estos términos son ejemplos de variantes gráficas, en el caso de dialoguista la Academia ha preferido esta forma desde la edición de 1936 y, en cambio, no ha aceptado en ninguna edición dialogista. De esta última variante existe una única documentación en el CORDE en un texto de Quevedo de 1609. La otra variante, dialoguista, es más frecuente en el español de América aunque también se recogen ejemplos en textos españoles del siglo Xx, a partir de 1980, como indican las consultas del CREA (Corpus de Referencia del Español Actual). En el segundo ejemplo, orictologista, el $D R A E$ ha optado por el lema mineralogista, formado a partir del sustantivo mineralogía, que también se documenta en Gaspar y Roig pero con la grafía 'j', característica en la ortografía de este lexicógrafo. En este caso, mineralogista existe anteriormente en el $D R A E$, a partir de la sexta edición (1822).

La hipótesis de la influencia de la lexicografía francesa en este diccionario también es visible, como en la obra de Domínguez. En cierta manera, el diccionario de Gaspar y Roig mantiene una relación de dependencia con esta obra anterior ya que muchas de las voces en -ismo e - ista que son propias del diccionario de Domínguez se recogen en este diccionario posterior. Como se puede observar en los siguientes ejemplos el diccionario de Gaspar y Roig mantiene los mismos criterios extensivos para la documentación de neologismos y tecnicismos:

\section{djainismo}

Filos. Sistema filosófico de algunos sabios de la Índia, que explica la formación del universo por el concurso de los átomos, con otros disparates por el estilo, que no carecen de originalidad é invención, si bien algunos datan de los mismos filósofos griegos (Domínguez 1853).

Filos. Sistema filosófico de algunos sabios de la India, que esplica la formación del universo por el concurso de los átomos homojéneos. Según ellos los seres animados son eternos y el alma lle- 
gara a la perfección cuando se vea libre de toda necesidad de obrar (Gaspar y Roig 1853).

fenicismo

Sistema engañoso de los fenicios, que con capa de comerciantes aspiraban a dominadores. ॥ Patol. V. SARAMPIÓN (Domínguez 1853).

Med. Nombre científico del sarampión (Gaspar y Roig 1853).

Junto a la vinculación de Domínguez también cabe señalar la influencia de los diccionarios franceses de la primera mitad del siglo XIX. Muchas de las palabras caracterizadas en este apartado en el diccionario de Gaspar y Roig se recogen con anterioridad en el diccionario de Bescherelle (1843). A continuación se cita un ejemplo:

\section{gnorista}

Zool. (que conoce): género de insectos dipteros de la familia de los fipniarios compuesto de una sola especie indígena de Prusia (Gaspar y Roig 1853).

s.m. Entom. Genre d'insectes diptères (Bescherelle 1843).

En definitiva, la existencia de los mismos tipos de voces en el Diccionario enciclopédico de la editorial Gaspar y Roig corrobora un fiel seguimiento hacia la obra de Domínguez y de Bescherelle. Este equipo de autores se basa en las mismas directrices para el diseño de su macroestructura. En ella subyace el criterio amplificador propio del género enciclopédico. Queda a su vez demostrada la influencia de las obras francesas del mismo periodo en este diccionario.

Finalmente, el último grupo de voces del Diccionario enciclopédico está compuesto por los derivados en -ismo e -ista que el equipo redactor recoge de la lexicografía académica y no académica anterior. Una parte significativa de voces, unas 358, procede de la novena edición del DRAE (1843). Sin embargo, en algunas ocasiones aparecen derivados que no forman parte de la novena edición (1843), es decir que sólo se documentaron en alguna edición anterior del siglo XVIII, o en el $D A$, y que aparecen en alguno de los diccionarios no académicos estudiados (anatocismo, galerista). En líneas generales, las voces que se adicionan con una fecha anterior en el $D R A E$ son términos que designan diferentes tipos de doctrinas (fatalismo, ostracismo, paganismo) y profesiones (metalista, mayorazguista, oculista).

Respecto a la tradición no académica anterior, un total de 308 voces se documenta en la obra de Domínguez (1853), 66 en la de Salvá (1846), 18 en la de Núñez de Taboada, 16 en la de Terreros y, finalmente, 15 en el diccionario de Castro y Rossi. El referente a Domínguez es claro tanto en la incorporación de voces procedente de su obra como en la adopción de su perspectiva lexicográfica. La tendencia a la incorporación de léxico científico y técnico es la que se practica en todos estos diccionarios anteriores al Diccionario enciclopédico y la mayor parte de las voces en -ismo e -ista que este diccionario hereda de los anteriores pertenece a este tipo de léxico.

\section{CONCLUSIONES}

El estudio de los derivados en -ismo e -ista en la lexicografía española monolingüe de la primera mitad del siglo XIX ha permitido confirmar la existencia de dos concepciones muy distantes en los diccionarios de esta época: una más abierta y permisiva ante la documentación de voces del lenguaje común y del léxico técnico y científico que corresponde a los diccionarios no académicos de esta época y otra, en cambio, más conservadora y más prudente ante la 
incorporación de voces que no tienen un uso extendido en la lengua común, criterio moderado que pertenece a la tradición de la Real Academia Española.

Esta perspectiva más tolerante hacia la aceptación indiscriminada de voces es un criterio que se ha observado en los cinco diccionarios no académicos escogidos. Precisamente esta gran diferencia con respecto al diccionario académico, esto es la presencia de un mayor número de voces en la nomenclatura de estos repertorios, es la que sirve a los autores de los diccionarios no académicos para publicar un producto lexicográfico más completo.

En los cinco diccionarios seleccionados se ha podido observar la presencia de un mismo tipo de voces en -ismo e -ista. Algunos de estos derivados llegan a tener un uso extendido y se admiten en alguna edición posterior del $D R A E$. Existe, en cambio, un conjunto importante de términos de los diccionarios no académicos que no llega a admitirse en ninguna edición del $D R A E$. La caracterización de este último grupo de voces permite justificar el motivo de su ausencia en las ediciones del $D R A E$.

Básicamente se han diferenciado cuatro tipo de voces: las voces específicas que pertenecen a campos muy concretos de la ciencia, la medicina, la historia o la religión; en segundo lugar, doctrinas antiguas y partidarios de ellas que se remontan a épocas anteriores desde la antigua Grecia hasta formas de pensamiento de los siglos XVII y XVIII y que, en general, son poco conocidas en el léxico del español común; en tercer lugar, con una menor representación se observa un conjunto voces vulgares o jocosas que por su definición pertenecen a un registro demasiado coloquial; finalmente, el último tipo de términos corresponde a variantes de otros lemas o formas que terminan con otros sufijos que se han aprobado en el $D R A E$.

Esta tipología de voces se acentúa en los años cincuenta de este siglo con la aparición en España de un nuevo género lexicográfico, el diccionario enciclopédico, visible en los diccionarios de Domínguez (1846-1847) y en el de la editorial Gaspar y Roig (1853). El afán acumulativo de todo tipo de voces se cumple fielmente en estos dos diccionarios. Como ha quedado demostrado en este estudio este carácter enciclopédico se relaciona con las obras lexicográficas francesas que conocieron ambos autores españoles. Se ha podido comprobar que un gran número de derivados en -ismo e -ista de estos diccionarios enciclopédicos españoles se recogen con anterioridad en los diccionarios franceses de Boiste (1834) y Bescherelle (1843).

En este sentido, estos dos diccionarios marcan un importante cambio en la evolución de la lexicografía española que originará entre otras cosas una revisión posterior de los criterios lexicográficos de la Corporación. La presión y las constantes críticas de estos lexicógrafos ante el escaso caudal léxico académico influyen en la flexibilidad que se observa en esta institución en las ediciones finales del siglo XIX. Así, como afirma Seco (1987: 139) gracias a este trabajo de revisión la Academia a partir de la duodécima edición (1884) acepta voces que ya se recogían desde años atrás en los diccionarios de Domínguez o Gaspar y Roig: «en virtud de este cambio de rumbo, entraron entonces por primera vez en el diccionario académico, o empezaron a entrar, multitud de voces que ya estaban en Domínguez y en Gaspar y Roig».

Finalmente, queda por destacar que los tres primeros diccionarios estudiados -el de Núñez de Taboada (1825), el de Salvá (1846) y el de Castro y Rossi (1852)-, comparten unas fuentes de procedencia parecidas. El corpus de voces en -ismo e -ista proviene fundamentalmente de tres fuentes documentales: El diccionario castellano de Terreros (1786-1788), la edición vigente del $D R A E$ a cada uno de estos diccionarios no académicos (la quinta de 1822 y la novena de 1843) y, finalmente, la influencia de los lexicógrafos anteriores, como Núñez de Taboada o Salvá, cuyas aportaciones particulares en -ismo e -ista se recogen en las obras pos- 
teriores de Castro y Rossi, Domínguez y Gaspar y Roig. Además de estas tres fuentes en los dos últimos diccionarios no académicos, el de Domínguez (1846-1847) y el de la editorial Gaspar y Roig (1853), cabe añadir la influencia francesa de los diccionarios de Boiste (1834) y Bescherelle (1843). En ambos diccionarios españoles aparecen palabras en -ismo e -ista que pertenecen a campos concretos de la ciencia y la medicina cuya presencia no se explica sino por la existencia de estas obras francesas y de otros textos escritos franceses de este periodo.

\section{REFERENCIAS BIBLIOGRÁFICAS}

Álvarez de Miranda, Pedro (2004): «Quevedo en la lexicografía española», Edad de Oro, XXIII, pp. 389-416.

Anglada Arboix, Emilia y María Bargalló Escrivà (1992): «Principios de lexicografía moderna en diccionarios del siglo XIX», en M. Ariza Viguera et al., eds., Actas del III Congreso Internacional de Historia de la Lengua Española, Madrid, Pabellón de España, I, pp. 955-962.

Azorín FERnÁNDEZ, Ma Dolores (1996): «La lexicografía española en el siglo XIX: Desarrollos y tendencias», en E. Serra et al., Panorama de la investigación lingüística a l'Estat Espanyol, Valencia, Universitat de València, pp. 48-54

(1996-1997): «La lexicografía española en el siglo XIX: del diccionario a la enciclopedia», Estudios de Lingüística de la Universidad de Alicante, 11, pp. 111-122.

- (2000): Los Diccionarios del español en su perspectiva histórica, Alicante, Universidad de Alicante.

- (2003): «Neologismos incorporados por Salvá en el Nuevo Diccionario de la Lengua Castellana», Estudios de Lingüística. Revista de Lengua Española y Lingüística General, 17, pp. 107-139.

— y Rosario BAQuero Mesa (1994-1995): «De la teoría a la práctica lexicográfica: El Nuevo diccionario de la lengua castellana de Vicente Salvá», Estudios de Lingüistica de la Universidad de Alicante, 10, pp. 9-20.

BAQUero Mesa, Rosario (1992): «Notas en contribución a la historia de la lexicografía española monolingüe del siglo XIX”, en Euralex'90 Proceedings. Actas del IV Congreso Internacional, Barcelona, Bibliograf, pp. 455- 461.

BRAY, Laurent (1990): «La lexicographie française des origines à Littré», en Franz Josef Hausmann et al., eds., Wörterbücher. Ein internationales Handbuch zur Lexikographie, Berlin-New York, Walter de Gruyter, II, pp. 1788-1818.

Bueno Morales, Ana (1996): «La lexicografía no académica del siglo XIX: el diccionario enciclopédico de la lengua española publicado por la editorial Gaspar y Roig», en Manuel Alvar Ezquerra, ed., Estudios de Historia de la Lexicografía del Español, Málaga, Universidad de Málaga, pp. 151-157.

DAVIES, Mark. Corpus del español, http://www.corpusdelespanol.org 
ESPARZA TORRES, Miguel Ángel (1999): «La lexicografía monolingüe española del siglo XIX: un conflicto de paradigmas», Romanistik in Geschichte und Gegenwart, 5/1, pp. 49-65.

FreiXAs AlÁs, Margarita (2003): Las autoridades en el primer diccionario de la Real Academia. Tesis doctoral inédita, Bellaterra, Universitat Autònoma de Barcelona. Disponible en http://www.tdx.cesca.es/TDX-0611104-150433.

_- (en prensa): «La lengua épica burlesca: la Mosquea de José de Villaviciosa (1615)», en Actas del X V Congreso Internacional de la Asociación Internacional de Hispanistas (Tecnológico de Monterrey, Monterrey, 19-24 de julio de 2004).

Garrido Moraga, Antonio Manuel (1992): «Un episodio en la lexicografía académica del siglo XVIII. Las supresiones en la segunda impresión del Diccionario», Rilce, 8/2, pp. 265-285.

García Platero, Juan Manuel (2003): «La lexicografía no académica en los siglos XVIII y XIX», en Antonia M. Medina Guerra, coord., Lexicografía española, Barcelona, Ariel, pp. 263-280.

Iglesia Martín, Sandra (2002): Las voces de la química en el Diccionario Nacional de R. J. Dominguez: la marcación y la definición. Trabajo de investigación inédito. Barcelona, IULA. Universitat Pompeu Fabra.

MenÉndez Pidal, Ramón (1945): «El diccionario que deseamos», Prólogo a Vox. Diccionario general ilustrado de la lengua española, Barcelona, Biblograf, pp. XXI-XXIX.

MuÑoz ARMiJo, Laura (2005): Los sufijos -ismo e -ista en el siglo XIX. Trabajo de investigación inédito. Bellaterra, Universidad Autónoma de Barcelona.

Pensado, Ma Carmen (1999): «Morfología y fonología. Fenómenos morfofonológicos», en Ignacio Bosque y Violeta Demonte, dirs., Gramática descriptiva de la lengua española, III: Entre la oración y el discurso. Morfología, Madrid, Espasa, pp. 4423-4504.

Real Academia Española: Banco de datos (CORDE) [en línea]. Corpus diacrónico del español. http://www.rae.es.

: Banco de datos (CREA) [en línea]. Corpus de referencia del español actual. http://www.rae.es.

SECO, Manuel (1987): Estudios de lexicografía española, Madrid, Paraninfo.

\section{OBRAS LEXICOGRÁFICAS}

BesCherelle, L. N. (1843): Dictionnaire nacional ou grand dictionnaire critique de la langue française, Paris. http://www.gallica.bnf.fr/ [en esta web aparece la cuarta edición, de 1856 de este diccionario].

BoISTE, P. C. v. (1834): Dictionnaire universal de la langue française, 8e éd., revue, corrigée et considérablement augmentée par Ch. Nodier, Paris.

CAStro y Rossi, Adolfo de (1852): Biblioteca Universal. Gran Diccionario de la Lengua Española [...] Tomo I, Madrid, Oficinas y establecimiento tipográfico del Seminario Pintoresco y de la Ilustración [consultado en la versión electrónica en DVD del NTLLE].

Centre National de la Recherche Scientifique (2004): Trésor de la Langue Française Informatisé (TLFI), CD-ROM, París, Université de Nancy.

Arnedo, Cipriano de y José CABallero (1849): Diccionario general de la lengua castellana: el mas manejable y completo, el mas inteligible y sucinto en sus definiciones y el mas uniforme en ortogra- 
fía (con arreglo á la Academia de la Lengua): contiene además el nombre de todos los pueblos de España y Ultramar con especificación de la distancia á que se hallan de las capitales de sus provincias, Madrid, Impr. Viuda de R. J. Domínguez.

Domínguez, Ramon Joaquín (1846-1847): Diccionario Nacional o Gran Diccionario Clásico de la Lengua Española, Madrid, Establecimiento de Mellado [1853, $5^{\text {a }}$ edición; consultado en la versión electrónica en DVD del NTLLE].

GaSPar y RoIg (1853-1855): Biblioteca Ilustrada Gaspar y Roig. Diccionario enciclopédico de la lengua española, con todas las vozes, frases, refranes y locuciones usadas en España y las Américas Españolas [...], Madrid, Imprenta y Librería de Gaspar y Roig, editores [consultado en la versión electrónica en DVD del NTLLE].

LABÈRNIA, Pere (1844-1848): Diccionario de la lengua castellana con las correspondencias catalana y latina, Barcelona, Imprenta de D. J. M. de Grau.

MARTY y CABALlero, Luis (1857): Vocabulario de todas las voces que faltan a los diccionarios de la lengua Castellana, Madrid.

NÚÑEZ DE TABOADA, Manuel (1825): Diccionario de la lengua castellana para cuya composición se han consultado los mejores vocabularios de esta lengua, y el de la Academia Española últimamente publicado en 1822, aumentado con más de 5000 voces o artículos que no se hallan en ninguno de ellos, 2 vols., París, Seguin [consultado en la versión electrónica en DVD del NTLLE].

Peñalver, Juan de (1842): Panléxico: Diccionario universal de la lengua castellana, Madrid, Imprenta de Ignacio Boix.

Pla y Torres, Cristóbal (1826): Diccionario de la lengua castellana por la Academia Española, París, Blanc.

Real Academia Española (2001): Nuevo Tesoro Lexicográfico de la Lengua Española (NTLLE), Madrid, Espasa, edición en DVD.

SALVÁ, Vicente (1846): Nuevo diccionario de la lengua castellana, que comprende la última edición íntegra, muy rectificada y mejorada del publicado por la Academia Española, y unas veinte y seis mil voces, acepciones, frases y locuciones, entre ellas muchas americanas [...], París, Vicente Salvá [consultado en la versión electrónica en DVD del NTLLE].

Terreros y Pando, Esteban de (1786-1788): Diccionario castellano con las voces de ciencias y artes y sus correspondientes en las tres lenguas francesa, latina e italiana [...], Madrid, Viuda de Ibarra [consultado en la versión electrónica en DVD del NTLLE].

ZEROLO, Elías (1895): Diccionario enciclopédico de la lengua castellana, París, Garnier Hermanos. 